\title{
Response Characteristics Analysis and Fatigue Life Assessment of Asphalt Pavement around the Manhole
}

\author{
Hong Zhang $\mathbb{D}^{1}{ }^{1}$ Quanman Zhao, ${ }^{2}$ and Can Peng ${ }^{3}$ \\ ${ }^{1}$ Qingdao Nearbridge Product Design Co., Ltd., Qingdao 26600, China \\ ${ }^{2}$ School of Transportation Engineering, Shandong Jianzhu University, Jinan 250101, China \\ ${ }^{3}$ State Key Laboratory of Traction Power, Southwest Jiaotong University, Chengdu 610031, China \\ Correspondence should be addressed to Hong Zhang; zhanghongpz@foxmail.com
}

Received 20 September 2020; Revised 24 November 2020; Accepted 3 December 2020; Published 21 December 2020

Academic Editor: Junyan Yi

Copyright $\odot 2020$ Hong Zhang et al. This is an open access article distributed under the Creative Commons Attribution License, which permits unrestricted use, distribution, and reproduction in any medium, provided the original work is properly cited.

In view of the damage of the pavement around manholes, this paper proposes an effective way to analyse the stress characteristics of the road under vehicle load and evaluate the fatigue life of the pavement around manholes. A half vehicle-road-manhole cover coupling dynamic model is established to calculate the dynamic load coefficient. According to the finite element analysis (FEA) model in ABQUS, the dynamic response characteristics of the pavement around the manhole are analysed, and the stresses under different braking force and different vehicle type are compared. In addition, the fatigue life of the pavement surface layer under different loading conditions is calculated, and three different fatigue life models are selected to analyse the influence of different factors on the fatigue life of the pavement base structure around the manhole. The results show that the fatigue life of the pavement base layer decreases with the increase of manhole subsidence value, and the fatigue life increases with the increase in thickness of the surface layer, and the change of elastic modulus of the subgrade has no obvious influence on the fatigue life of road base. Finally, a fatigue life evaluation index based on high root energy is proposed to compare the three models more intuitively. Consequently, the analysis results can provide a basis for manhole surrounding pavement design and maintenance, and the analysis method is worthy of further application in the research of pavement fatigue life under more influencing factors.

\section{Introduction}

With the rapid development of urban infrastructure, as a basic component of municipal facilities, manholes used for power transmission, gas transmission, and communication transmission inevitably exist in urban roads. The pavement around the manhole is vulnerable to damage. According to statistical analysis, the common damage forms of the pavement around the manhole are crack, separation of the pavement from the manhole, and the depression of the manhole, as shown in Figure 1. Li [1] calculated the distribution of cracks and subsidence damage on the pavement around the manhole, in which cracks accounted for $65.09 \%$ and subsidence accounted for $63.2 \%$. At the same time, they analysed the possible causes of cracks and subsidence. Usama [2] investigated the distresses of manhole pavement in different severity levels and established the relationship between the geometries of manholes and the quantity of distresses.

The occurrence of damage not only affects driving comfort and safety but also greatly reduces the service life of the road. The life assessment of asphalt pavement around the manhole should not only need to consider its own structure and construction conditions but also the surrounding environment and the effect of random dynamic loads of vehicles. Vehicle-pavement structure is a complex motion system that integrates multiple motion characteristics. The dynamic response characteristics of the road under vehicle load have a great relationship with vehicle load configuration, road roughness, and driving speed [3,4]. Ling et al. [5] proposed a semianalytical finite element method based on 


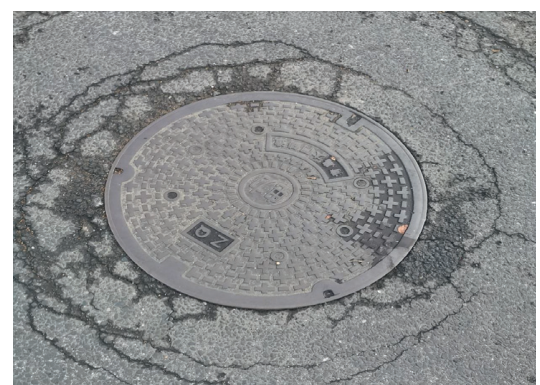

(a)

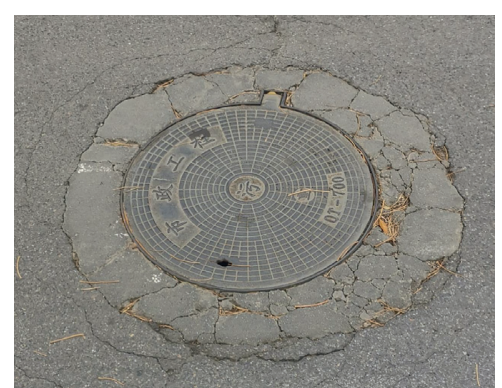

(b)

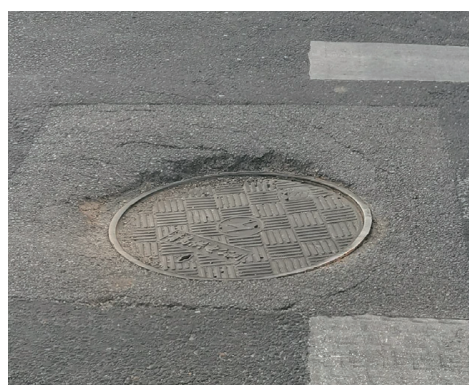

(c)

Figure 1: Common damage forms of the pavement around the manhole. (a) Crack. (b) Separation of the pavement from the manhole. (c) Subsidence of the manhole.

transverse fast Fourier transform (FFT) to analyse the dynamic response and stress path of pavement under the action of moving aircraft load. Galvín et al. [6] presented a fully three-dimensional nonlinear vehicle-track-soil-structure finite element boundary element model to study the dynamic behaviour of the multibody system. Eslaminia et al. [7] proposed a Fourier-finite element method combined with time-scale separation-based ideas to predict progressive pavement distress under millions of cycles of moving vehicular loading. Hu et al. [8] established a vibration model with multi-degree of freedom for vehicle-manhole cover to investigate the damage affect to pavement around the manholes. Yan et al. [9] constructed a subgrade-surface discrete element model to investigate the failure mechanism of asphalt pavement under the mesoscopic response which suffered from vibration.

The stress analysis of pavement around the manhole involves to study the dynamic stress change under the load generated by vehicles when entering and leaving the road area. It is considered that the stress and strain of pavement will change greatly with the change of load position. Wei et al. [10] compared the stress of the concrete pavement around the manhole in different parameters when the vehicle enters and exits. It is found that the compressive stress of the top layer and the tensile stress of the bottom layer firstly increase and then decrease as the vehicles enter and exit. Brown and Brown [11] concluded that the failures of pavement around the manhole are probably caused by a combination of shear and tensile stresses induced by the differential vertical stiffness of the pavement and the chamber. Lin et al. [12] found that the maximum principal strain in the horizontal direction occurs at the bottom of the overlaying course in the pavement, where the maximum compressive strain in the vertical direction occurs at the interface between the manhole cover and the around asphalt concrete pavement.

Fatigue damage and permanent deformation are the main failure forms of asphalt pavement. Fatigue damage includes the damage of pavement surface layer and the base layer, which seriously affects the service life of the road. At present, fatigue test methods are commonly used to estimate the fatigue properties of asphalt pavement, and the fatigue damage performance of asphalt is characterized by quantified characteristic indexes such as section index and flatness index [13]. Dilip et al. [14] carried out the reliability analysis for a flexible pavement section to identify the critical parameter affecting the design reliability for both fatigue and rutting failure criteria. Hintz and Bahia [15] demonstrated that fracture can explain the changes in loading resistance during fatigue testing in the dynamic shear rheometer and proposed an analysis framework to predict binder fatigue life at various loads using the single time sweep test result. Ning et al. [16] proposed a new fatigue analysis method to compare the fatigue relations obtained from combinations of test types and specimen sizes. Yared and Bjorn [17] proposed a new mechanics-based analysis framework to study the influence of axle load spectra and other traffic characterization parameters on fatigue cracking performance prediction.

Two main purposes in this study are described as follows.

(1) To obtain the dynamic response characteristics of the pavement around the manhole based on the vehicleroad-manhole cover dynamic model and finite element simulation and to compare the influences of different braking forces and different vehicle types on the pavement.

(2) To calculate the fatigue life of the pavement surface layer and the base layer based on the mechanical response results of the road and analyse the influence of different factors on the fatigue life of the base layer so as to provide a basis for the design and maintenance of the pavement around the manhole.

The specific structure of this paper is shown in Figure 2. Firstly, a multi-degree-of-freedom dynamic model based on $1 / 2$ vehicle-road-manhole cover coupling is established, and the dynamic load distribution characteristics of vehicles passing through the manhole are obtained. Then, based on the ABQUS finite element analysis (FEA) software, the dynamic stress response distribution of the semirigid asphalt pavement around 
the manhole under the vehicle loads is calculated. Subsequently, based on the results of the pavement stress response under different working conditions, the fatigue life of the asphalt pavement surface layer and the base layer is evaluated, and the influence of the three fatigue life analysis models for the pavement base layer was compared and analysed.

\section{Response Characteristics for Vehicle- Pavement-Manhole Dynamic Model}

2.1. Establishing a Coupled Dynamic Model. When the vehicle passes the manhole and the surrounding pavement, the vibration characteristics of the vehicle are obviously different from those of the ordinary pavement. When a vehicle passes through an ordinary pavement, the vehicle and the pavement will be a dual coupling system. When the vehicle passes through a manhole, the manhole cover will vibrate randomly. Therefore, the vehicle, the pavement, and the manhole cover will be a ternary coupling system. Here we use heavy truck and car to build the simulation model, respectively, without considering the influence of road roughness.

A heavy truck with a $6 \times 4$ structure layout is used to establish a $1 / 2$ vehicle-road-manhole cover coupling dynamic simplified model. In this paper, the front axle of the vehicle is selected as the analysis object. The establishment of the dynamic model of the vehicle's front wheel in the road surface area around the manhole and in the manhole cover area is shown in Figure 3. Similarly, the dynamic model for a car is shown in the Figure 4.

As shown in Figure 3(a), when the front wheel of the heavy truck is in the area around the manhole, the manhole cover is not subject to load. Assuming that the road base does not vibrate with the vehicle, the displacement matrix when the front wheel of the vehicle is in the area around the manhole is as follows:

$$
Y 1 a=\left[\begin{array}{llllllllll}
y 1 & \dot{y} 1 & y 2 & \dot{y} 2 & y 3 & \dot{y} 3 & y 4 & \dot{y} 4 & \theta & \dot{\theta}
\end{array}\right]^{T} .
$$

Similarly, according to Figure 4(a), the displacement matrix for car is as follows:

$$
Y 1 b=\left[\begin{array}{llllllll}
y 1 & \dot{y} 1 & y 2 & \dot{y} 2 & y 3 & \dot{y} 3 & \theta & \dot{\theta}
\end{array}\right]^{T} .
$$

Then, the differential matrix equation of the $1 / 2$ vehicleroad coupling dynamic simplified model under this working condition is as follows:

$$
\dot{Y} 1=A 1 Y 1 .
$$

The coefficient matrix for the heavy truck is as follows:

$$
A 1 a=\left[\begin{array}{cccccccccc}
0 & 1 & 0 & 0 & 0 & 0 & 0 & 0 & 0 & 0 \\
-\frac{k 1+k 3+k 5}{m 1} & -\frac{c 1+c 3++c 5}{m 1} & \frac{k 1}{m 1} & \frac{c 1}{m 1} & \frac{k 3}{m 1} & \frac{c 3}{m 1} & \frac{k 5}{m 1} & \frac{c 5}{m 1} & 0 & 0 \\
0 & 0 & 0 & 1 & 0 & 0 & 0 & 0 & 0 & 0 \\
\frac{k 1}{m 1} & \frac{c 1}{m 2} & \frac{k 2+k 1}{m 2} \frac{c 2+c 1}{m 2} & 0 & 0 & 0 & 0 & 0 & 0 \\
0 & 0 & 0 & 0 & 0 & 1 & 0 & 0 & 0 & 0 \\
\frac{k 3}{m 3} & \frac{c 3}{m 3} & 0 & 0 & -\frac{k 4+k 3}{m 3} & -\frac{c 4+c 3}{m 3} & 0 & 0 & 0 & 0 \\
0 & 0 & 0 & 0 & 0 & 0 & 1 & 0 & 0 \\
\frac{k 5}{m 4} & \frac{c 5}{m 4} & 0 & 0 & 0 & 0 & -\frac{k 6+k 5}{m 4} & -\frac{c 6+c 5}{m 4} & 0 & 0 \\
0 & 0 & 0 & 0 & 0 & 0 & 0 & 0 & 1 \\
\frac{k 1 L 1-k 3 L 2-k 5 L 3}{J} \frac{c 1 L 1-c 3 L 2-c 5 L 3}{J} & -\frac{k 1 L 1}{J} & -\frac{c 1 L 1}{J} & \frac{k 3 L 2}{J} & \frac{c 3 L 2}{J} & \frac{k 5 L 3}{J} & \frac{c 5 L 3}{J} & 0 & 0
\end{array}\right] .
$$




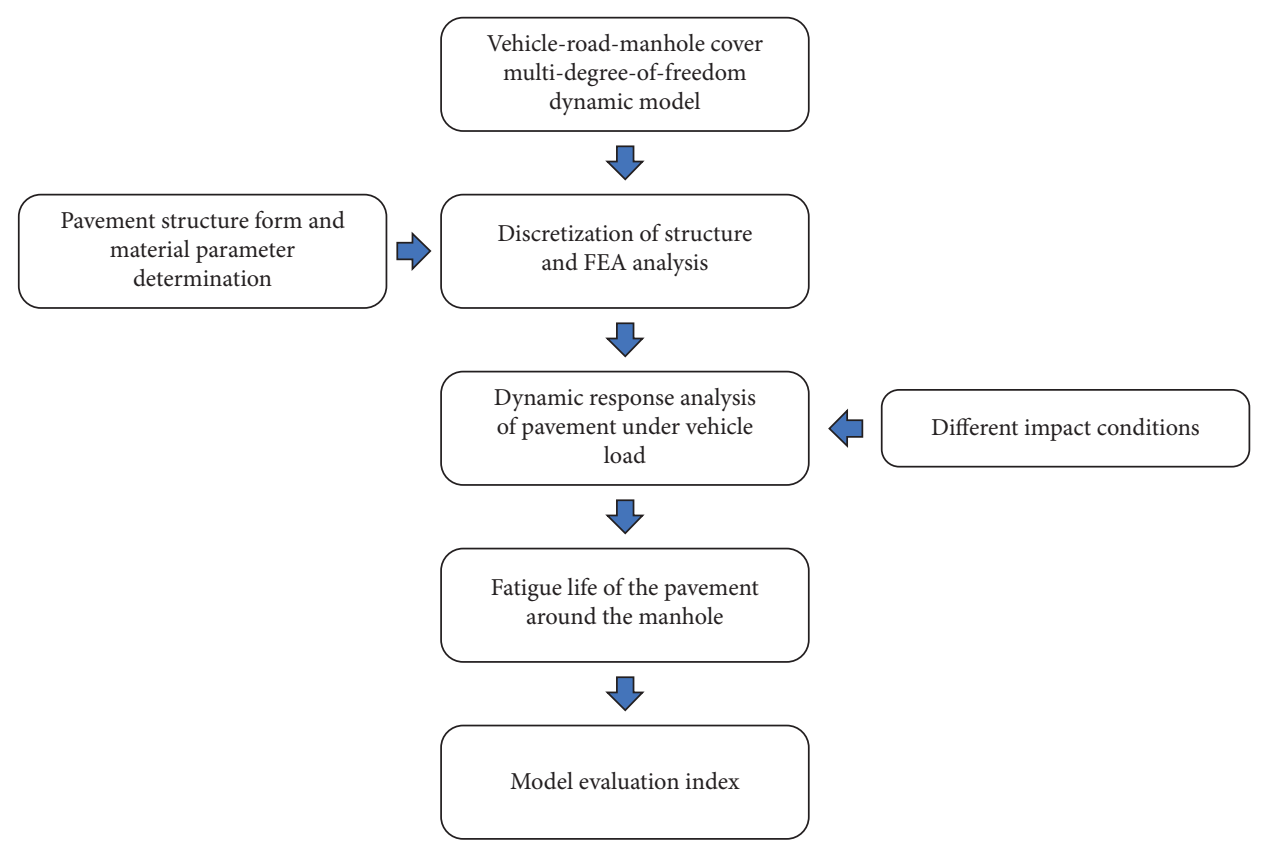

FIGURE 2: Specific process for response characteristics analysis and life assessment of asphalt pavement around the manhole.

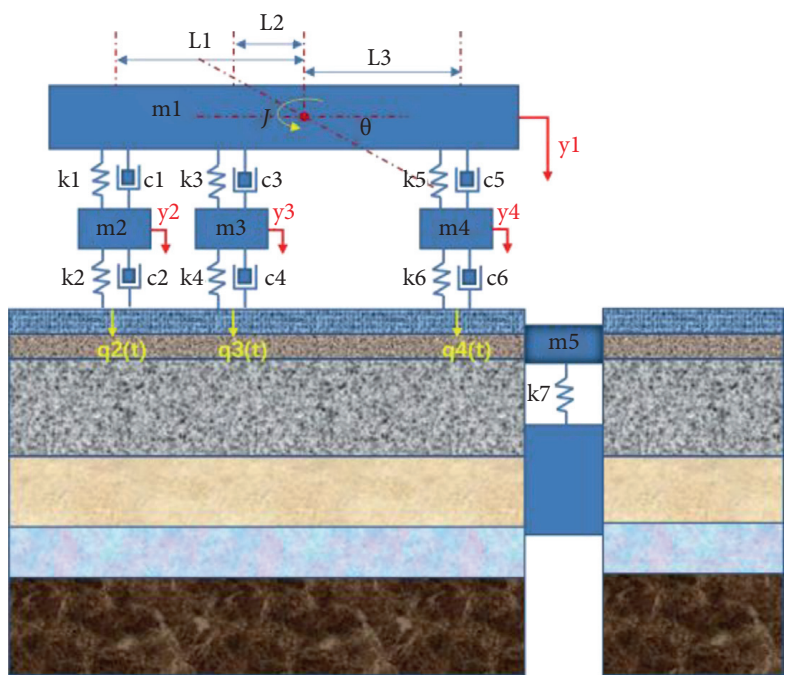

(a)

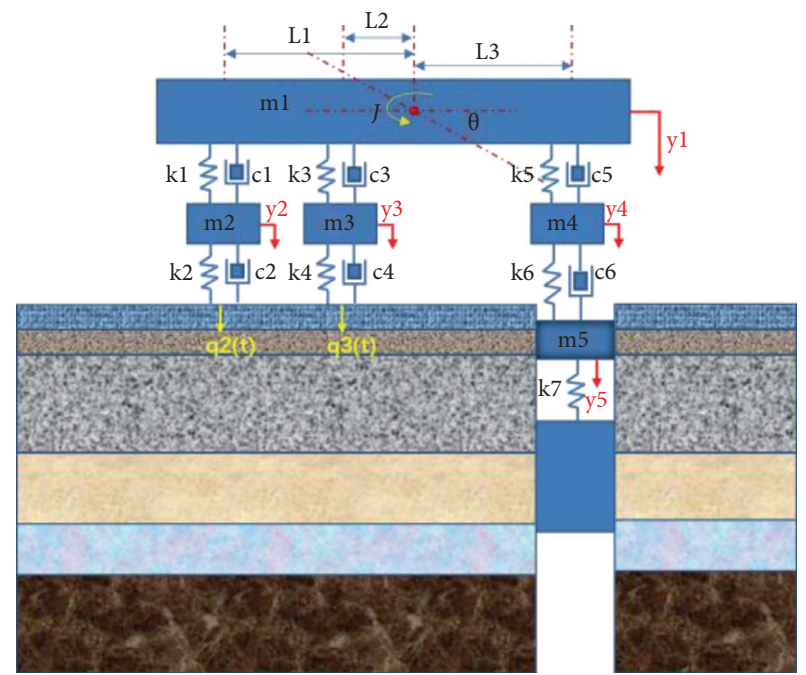

(b)

FIgURe 3: Truck-pavement-manhole cover dynamic model. (a) The front wheel is on the road surface area around the well. (b) The front wheel of the vehicle is on the manhole cover area. 


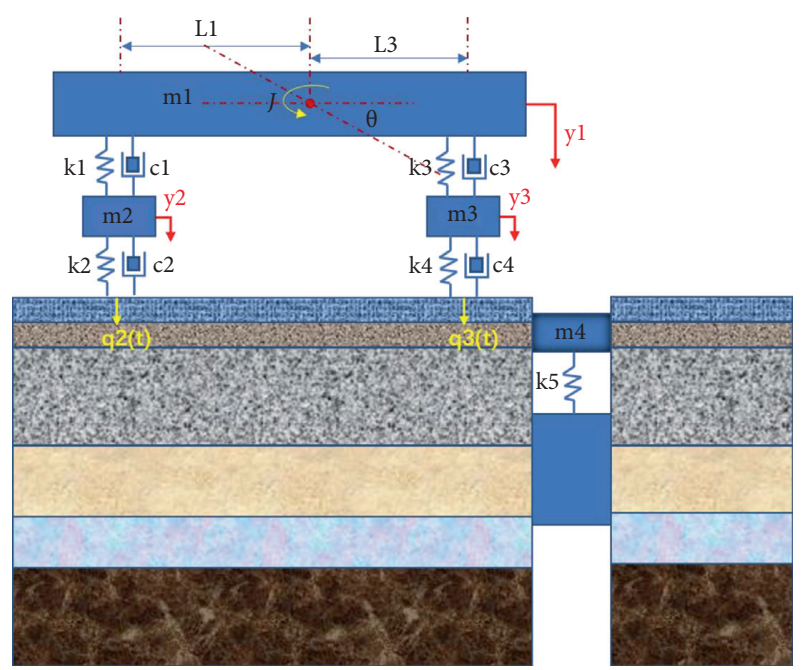

(a)

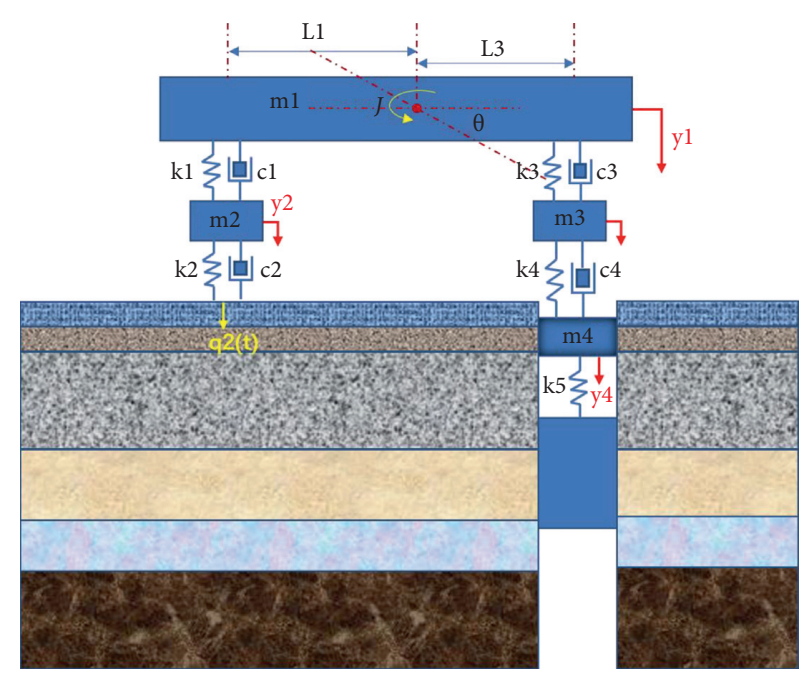

(b)

FIGURE 4: Car-pavement-manhole cover dynamic model. (a) The front wheel is on the road surface area around the well. (b) The front wheel of the vehicle is on the manhole cover area.

Similarly, the coefficient matrix for the car is as follows:

$$
A 1 b=\left[\begin{array}{cccccccc}
0 & 1 & 0 & 0 & 0 & 0 & 0 & 0 \\
-\frac{k 1+k 3}{m 1} & -\frac{c 1+c 3}{m 1} & \frac{k 1}{m 1} & \frac{c 1}{m 1} & \frac{k 3}{m 1} & \frac{c 3}{m 1} & 0 & 0 \\
0 & 0 & 0 & 1 & 0 & 0 & 0 & 0 \\
\frac{k 1}{m 2} & \frac{c 1}{m 2} & -\frac{k 2+k 1}{m 2} & -\frac{c 2+c 1}{m 2} & 0 & 0 & 0 & 0 \\
0 & 0 & 0 & 0 & 0 & 1 & 0 & 0 \\
\frac{k 3}{m 3} & \frac{c 3}{m 3} & 0 & 0 & -\frac{k 4+k 3}{m 3} & -\frac{c 4+c 3}{m 3} & 0 & 0 \\
0 & 0 & 0 & 0 & 0 & 0 & 1 \\
\frac{k 1 L 1-k 3 L 3}{J} & \frac{c 1 L 1-c 3 L 3}{J} & -\frac{k 1 L 1}{J} & -\frac{c 1 L 1}{J} & \frac{k 3 L 3}{J} & \frac{c 3 L 3}{J} & 0 & 0
\end{array}\right]
$$

Then, the result of solving equation (2) is as follows:

$$
Y 1(t)=A 1 e^{A 1 t} Y 1(0) \text {. }
$$

As shown in Figure 3(b), when the front wheel of the heavy truck is in the manhole cover area, the manhole cover is under load. Assuming that the road base does not randomly vibrate with the vehicle, the displacement matrix when the front wheel of the vehicle is in the manhole cover area is as follows:

$$
Y 1 a=\left[\begin{array}{llllllllllll}
y 1 & \dot{y} 1 & y 2 & \dot{y} 2 & y 3 & \dot{y} 3 & y 4 & \dot{y} 4 & y 5 & \dot{y} 5 & \theta & \dot{\theta}
\end{array}\right]^{T} .
$$

Similarly, according to Figure 4(b), the displacement matrix for the car is as follows:

$$
Y 2 b=\left[\begin{array}{llllllllll}
y 1 & \dot{y} 1 & y 2 & \dot{y} 2 & y 3 & \dot{y} 3 & y 4 & \dot{y} 4 & \theta & \theta
\end{array}\right]^{T} .
$$

Then, the differential matrix equation of $1 / 2$ vehicleroad-manhole cover coupling dynamic simplified model under this working condition is as follows:

$$
\dot{Y} 2=A 2 Y 2
$$

The coefficient matrix for the heavy truck is as follows: 


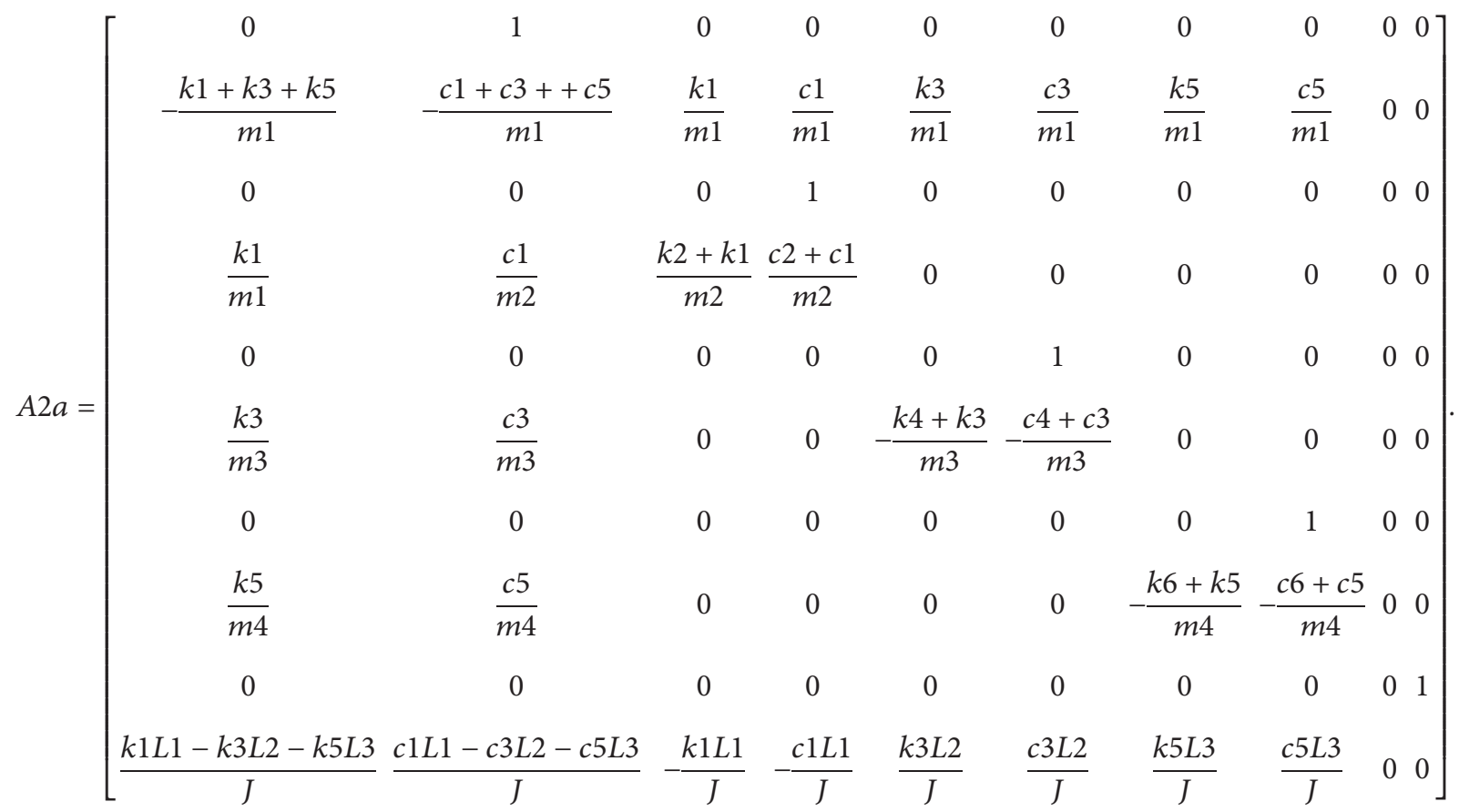

Similarly, the coefficient matrix for the car is as follows:

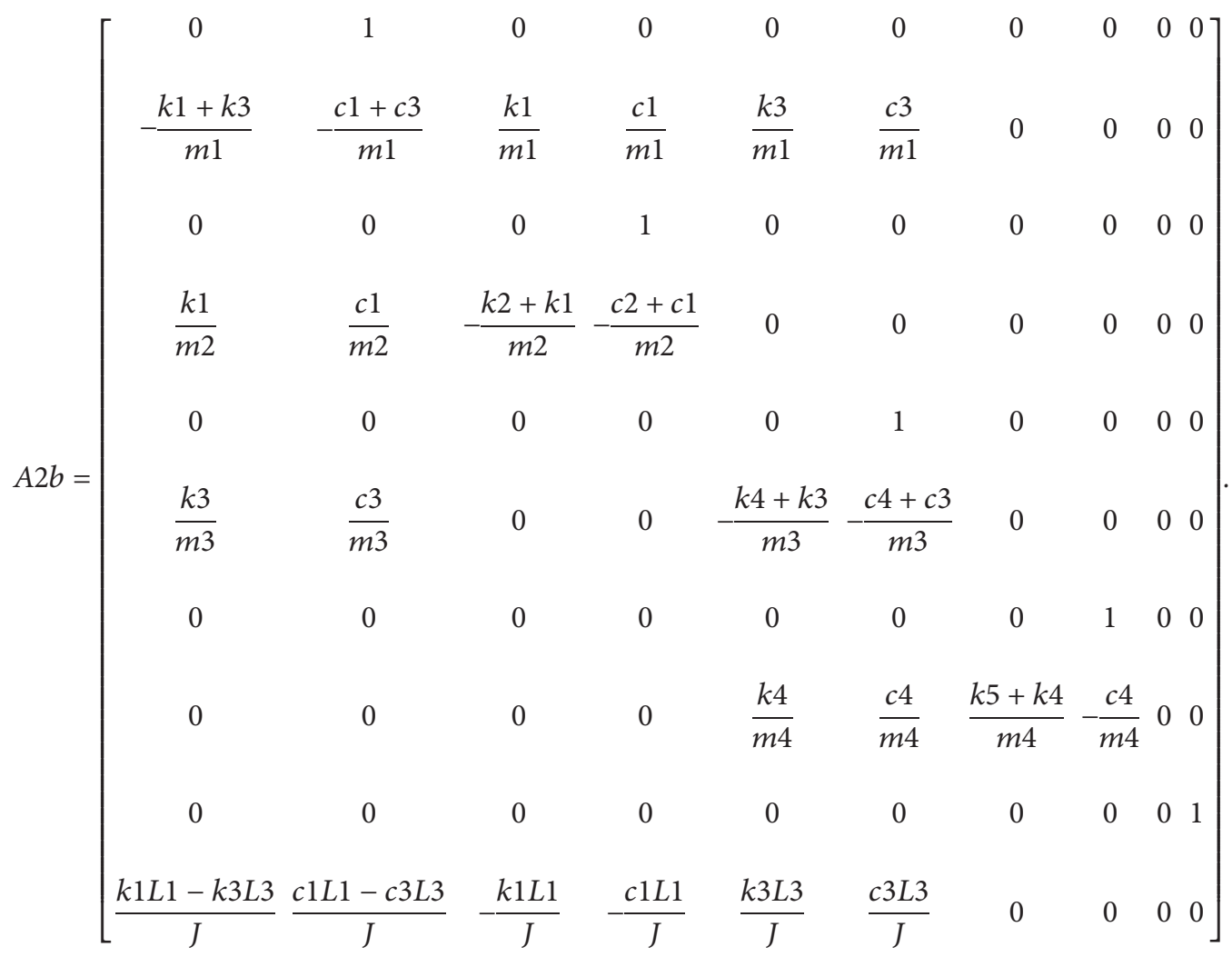

Then, the result of solving equation (7) is as follows:

$$
Y 2(t)=A 2 e^{A 2 t} Y 2(0)
$$

2.2. Dynamic Load Coefficient under Different Road Conditions. In order to obtain the dynamic load coefficient according to equations (5) and (10), the vehicle speed is set to 
$30 \mathrm{~km} / \mathrm{h}$, the road gradient is set to $4 \%$, and the subsidence value of the manhole is set to from 0.01 to $0.06 \mathrm{~m}$, respectively [18-20]. According to the ordinary road parameters in China, the initial conditions $Y 1(0)$ and $Y 2(0)$ are as shown in Table 1.

According to the design conditions of a heavy truck with a $6 \times 4$ structure layout, the relevant parameters of the dynamic model are set as shown in Table 2 [21].

According to the design conditions of a car, the relevant parameters of the dynamic model are set as shown in Table 3 [22].

According to the dynamic model shown in Figure 2, the static load on the front wheel of the heavy truck is

$$
F a=m 4 g+\frac{L 1+L 2}{L 1+L 2+2 \times L 3} m 1 g .
$$

The static load on the front wheel of the car is

$$
F b=m 3 g+\frac{L 1}{L 1+L 3} m 1 g \text {. }
$$

The impact dynamic load on the road surface or manhole cover under the front wheel of the heavy truck is

$$
F a(t)=k 6 y 4+c 6 y 4
$$

The impact dynamic load on the road surface or manhole cover under the front wheel of the car is

$$
F b(t)=k 4 y 3+c 4 y 3
$$

Then, the front wheel dynamic load factor is

$$
f=1+\frac{F(t)}{F} \text {. }
$$

Through the above calculation, the dynamic load coefficient of the front wheel being on the road surface area and on the manhole cover area under three different manhole subsidence values is shown in Figures 5 and 6. It can be seen that the dynamic load will increase when the vehicle enters the manhole cover area due to the transient shock. Subsequently, the dynamic load will decrease to low value when the vehicle returns to the pavement around the manhole. Compared with the car, the dynamic load produced by the heavy truck changes more significantly. Moreover, it can be seen that the maximum dynamic load coefficient of the front wheel increases with the expansion of the manhole subsidence. The maximum dynamic load coefficient of the front wheel is illustrated in Table 4.

\section{Finite Element Simulation of the Pavement around the Manhole}

3.1. FEA Model of the Pavement around the Manhole. Referring to the asphalt pavement design specification of China [23], the structure of the asphalt pavement with semirigid base is determined. Commercial ABAQUS software is used to build a three-dimensional pavement FEA model. The modelling process mainly includes the following.
3.1.1. Determination of Structure and Material Parameters. A three-dimensional pavement model including the manhole structure is built with the size of $6 \mathrm{~m} \times 3.5 \mathrm{~m} \times 4 \mathrm{~m}$, as shown in Figure 7 . The structure parameters of each layer are shown in Table 5 [24]. The manhole structure adopts a self-adjusting structure, including manhole cover, wellbore, and well chamber. Since the study object is the pavement around the manhole, the manhole structure is constrained as a rigid body, and the stress changes inside it will be ignored. In ABAQUS, the viscoelasticity of asphalt materials is defined by Prony series, as shown in Table 6 [25].

3.1.2. Defining Boundary Conditions. Assuming that all of the materials are isotropic, the contact between the layers of the pavement is completely continuous, and the other structural layer materials outside the surface layer are linear elastic. In the model, the bottom surface of the model is set as full constraint, the vertical ( $Z$ direction) displacement is constrained in the surfaces that are perpendicular to the $X$ direction, and the longitudinal ( $X$ direction) displacement is constrained in surfaces that are perpendicular to the $Y$ direction [26]. The processed model is shown in Figure 8.

3.1.3. Defining Load Conditions. The pavement surface area near the manhole is selected as the loading area with a length of $1.5 \mathrm{~m}$. The load value is obtained according to the vehicle parameters in Tables 2-3 and the dynamic load coefficient in Table 4, and the loading area of each incremental step is equivalent to a rectangular of $0.192 \times 0.186 \mathrm{~m}$ [24]. In the software, the movement of the load on the road surface is realized by VDLOAD and UTRACLOAD subroutines, and the moving speed of the load can be controlled by the analysis step time set in the software.

\subsection{Dynamic Response Characteristics of the Pavement around} the Manhole. The dynamic stress with different pavement depths under longitudinal and vertical loads of heavy truck is obtained by finite element simulation. In this case, the vehicle speed is $30 \mathrm{~km} / \mathrm{h}$, and the manhole subsidence value is $0.01 \mathrm{~m}$. The stresses of the pavement in three directions with a depth of $0 \mathrm{~m}$ to $0.76 \mathrm{~m}$ are shown in Figures 9-11. It can be seen that these curves reflect the loading process when the load enters and leaves the observation area. When the load approaches and leaves this position, the stress in the pavement produces the phenomenon of positive and negative alternations, and this alternation of stress is an important factor causing fatigue damage to materials. In addition, the figures also show that with the increase of pavement depth, the stress in three directions decreases rapidly, and the vertical dynamic stress is greater than the axial and longitudinal dynamic stress. When the pavement depth is greater than $0.76 \mathrm{~m}$, which is the subgrade layer of the road, the stress value is already very small.

3.3. Response of the Pavement around the Manhole under Different Braking Forces and Different Vehicle Types. In the actual situation, when the vehicle passes the pavement with a 
TABLE 1: Initial condition values under different working conditions.

\begin{tabular}{|c|c|c|}
\hline $\begin{array}{l}\text { Working } \\
\text { condition }\end{array}$ & Initial condition for $Y 1(0)$ & Initial condition for $Y 2(0)$ \\
\hline $\begin{array}{l}(4 \%, 0.01 \mathrm{~m}, \\
30 \mathrm{~km} / \mathrm{h})\end{array}$ & 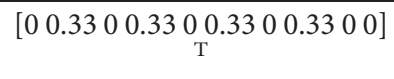 & $\begin{array}{c}\mathrm{YY} 1(1, \mathrm{t} 1) \mathrm{Y} 1(2, \mathrm{t} 1) \mathrm{Y} 1(3, \mathrm{t} 1) \mathrm{Y} 1(4, \mathrm{t} 1) \mathrm{Y} 1(5, \mathrm{t} 1) \mathrm{Y} 1(6, \mathrm{t} 1) \mathrm{Y} 1(7, \mathrm{t} 1)+0.01 \mathrm{Y} 1(8, \mathrm{t} 1) 0 \\
0\end{array}$ \\
\hline $\begin{array}{l}(4 \%, 0.03 \mathrm{~m} \\
30 \mathrm{~km} / \mathrm{h})\end{array}$ & 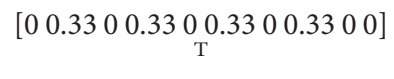 & $\begin{array}{c}\mathrm{Y} 1(1, \mathrm{t} 1) \mathrm{Y} 1(2, \mathrm{t} 1) \mathrm{Y} 1(3, \mathrm{t} 1) \mathrm{Y} 1(4, \mathrm{t} 1) \mathrm{Y} 1(5, \mathrm{t} 1) \mathrm{Y} 1(6, \mathrm{t} 1) \mathrm{Y} 1(7, \mathrm{t} 1)+0.03 \mathrm{Y} 1(8, \mathrm{t} 1) 0 \\
00\end{array}$ \\
\hline $\begin{array}{l}(4 \%, 0.06 \mathrm{~m} \\
30 \mathrm{~km} / \mathrm{h})\end{array}$ & 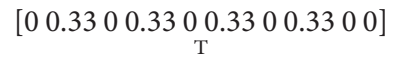 & $\begin{array}{c}{[\mathrm{Y} 1(1, \mathrm{t} 1) \mathrm{Y} 1(2, \mathrm{t} 1) \mathrm{Y} 1(3, \mathrm{t} 1) \mathrm{Y} 1(4, \mathrm{t} 1) \mathrm{Y} 1(5, \mathrm{t} 1) \mathrm{Y} 1(6, \mathrm{t} 1) \mathrm{Y} 1(7, \mathrm{t} 1)+0.06 \mathrm{Y} 1(8, \mathrm{t} 1) 0} \\
0\end{array}$ \\
\hline
\end{tabular}

TABle 2: Dynamic model parameters of heavy truck.

\begin{tabular}{lc}
\hline Parameters & Value \\
\hline$m_{1}(\mathrm{~kg})$ & 15950 \\
$m_{2}(\mathrm{~kg})$ & 1000 \\
$m_{3}(\mathrm{~kg})$ & 1000 \\
$m_{4}(\mathrm{~kg})$ & 700 \\
$m_{5}(\mathrm{~kg})$ & 56 \\
$c 1(\mathrm{~N} \cdot \mathrm{s} / \mathrm{m})$ & 14000 \\
$c 2(\mathrm{~N} \cdot \mathrm{s} / \mathrm{m})$ & 3000 \\
$c 3(\mathrm{~N} \cdot \mathrm{s} / \mathrm{m})$ & 14000 \\
$c 4(\mathrm{~N} \cdot \mathrm{s} / \mathrm{m})$ & 3000 \\
$c 5(\mathrm{~N} \cdot \mathrm{s} / \mathrm{m})$ & 10000 \\
$c 6(\mathrm{~N} \cdot \mathrm{s} / \mathrm{m})$ & 3000 \\
$k 1(\mathrm{~N} / \mathrm{m})$ & $2.5 \times 10^{6}$ \\
$k 2(\mathrm{~N} / \mathrm{m})$ & $2 \times 10^{6}$ \\
$k 3(\mathrm{~N} / \mathrm{m})$ & $2.5 \times 10^{6}$ \\
$k 4(\mathrm{~N} / \mathrm{m})$ & $2 \times 10^{6}$ \\
$k 5(\mathrm{~N} / \mathrm{m})$ & $4 \times 10^{5}$ \\
$k 6(\mathrm{~N} / \mathrm{m})$ & $1.9 \times 10^{6}$ \\
$k 7()$. & $9 \times 10^{6}$ \\
$J\left(\mathrm{~N} \cdot \mathrm{m}^{2}\right)$ & 190512 \\
$L 1(\mathrm{~m})$ & 1.515 \\
$L 2(\mathrm{~m})$ & 0.505 \\
$L 3(\mathrm{~m})$ & 3.15 \\
\hline
\end{tabular}

TABle 3: Dynamic model parameters of car.

\begin{tabular}{lc}
\hline Parameters & Value \\
\hline$m_{1}(\mathrm{~kg})$ & 1484 \\
$m_{2}(\mathrm{~kg})$ & 82 \\
$m_{3}(\mathrm{~kg})$ & 82 \\
$m_{4}(\mathrm{~kg})$ & 56 \\
$c 1(\mathrm{~N} \cdot \mathrm{s} / \mathrm{m})$ & 2000 \\
$c 2(\mathrm{~N} \cdot \mathrm{s} / \mathrm{m})$ & 15000 \\
$c 3(\mathrm{~N} \cdot \mathrm{s} / \mathrm{m})$ & 10000 \\
$c 4(\mathrm{~N} \cdot \mathrm{s} / \mathrm{m})$ & 2000 \\
$k 1(\mathrm{~N} / \mathrm{m})$ & 41000 \\
$k 2(\mathrm{~N} / \mathrm{m})$ & $2 \times 10^{5}$ \\
$k 3(\mathrm{~N} / \mathrm{m})$ & 26000 \\
$k 4(\mathrm{~N} / \mathrm{m})$ & $2 \times 10^{5}$ \\
$k 5(\mathrm{~N} / \mathrm{m})$ & $9 \times 10^{6}$ \\
$J\left(\mathrm{~N} \cdot \mathrm{m}^{2}\right)$ & 2805 \\
$L 1(\mathrm{~m})$ & 1.45 \\
$L 3(\mathrm{~m})$ & 1.3 \\
\hline
\end{tabular}

manhole, the vehicle will generally go through a process of deceleration and acceleration. In order to study the influence of different braking forces and traction forces caused by the change of vehicle speed, different longitudinal loads of heavy truck with the vehicle acceleration of $3 \mathrm{~m} / \mathrm{s}^{2}, 6 \mathrm{~m} / \mathrm{s}^{2}$, and $9 \mathrm{~m} /$ $\mathrm{s}^{2}$ are applied to the model.

The change of longitudinal force has a great influence on the shear stress of pavement structure. The shear stress 

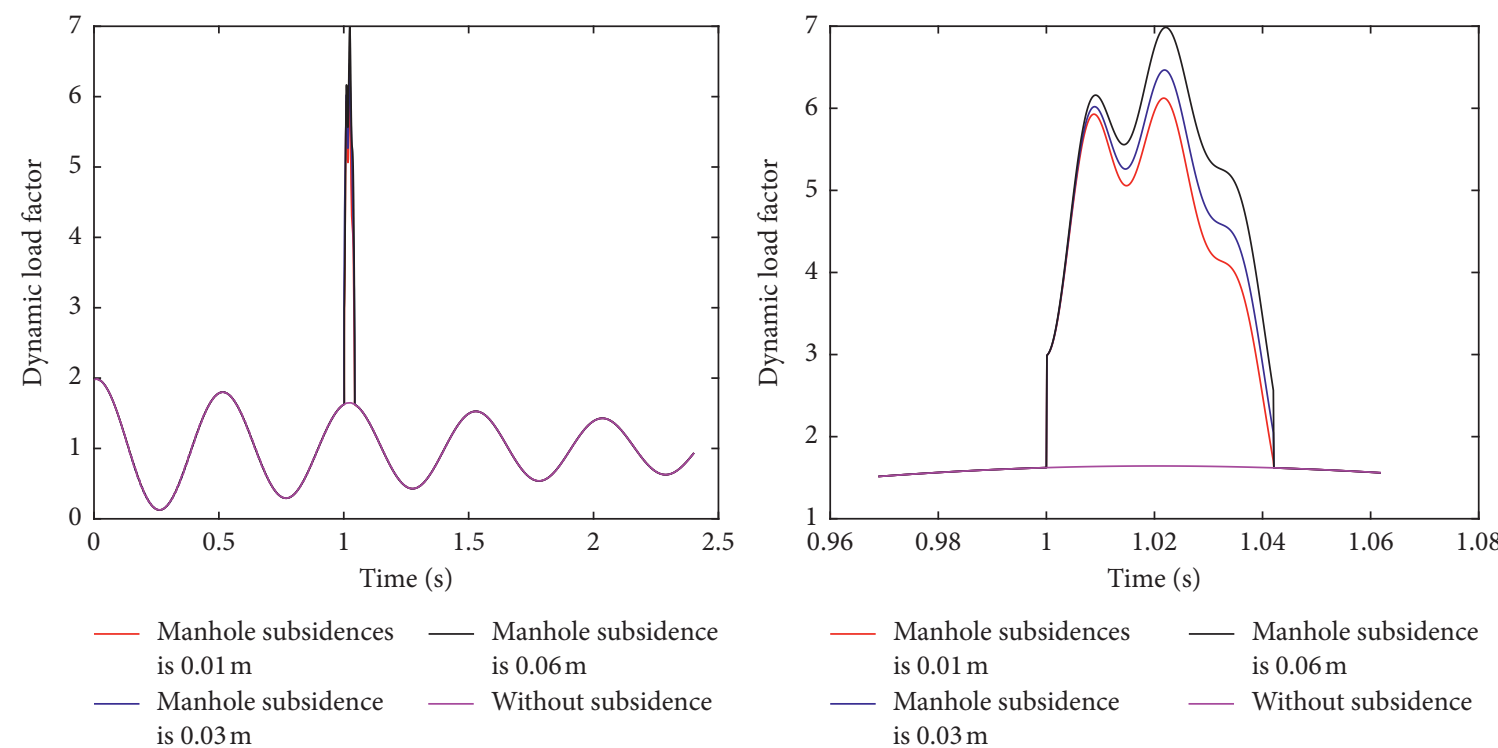

Figure 5: Vehicle dynamic load coefficient under different manhole subsidence values for heavy truck.
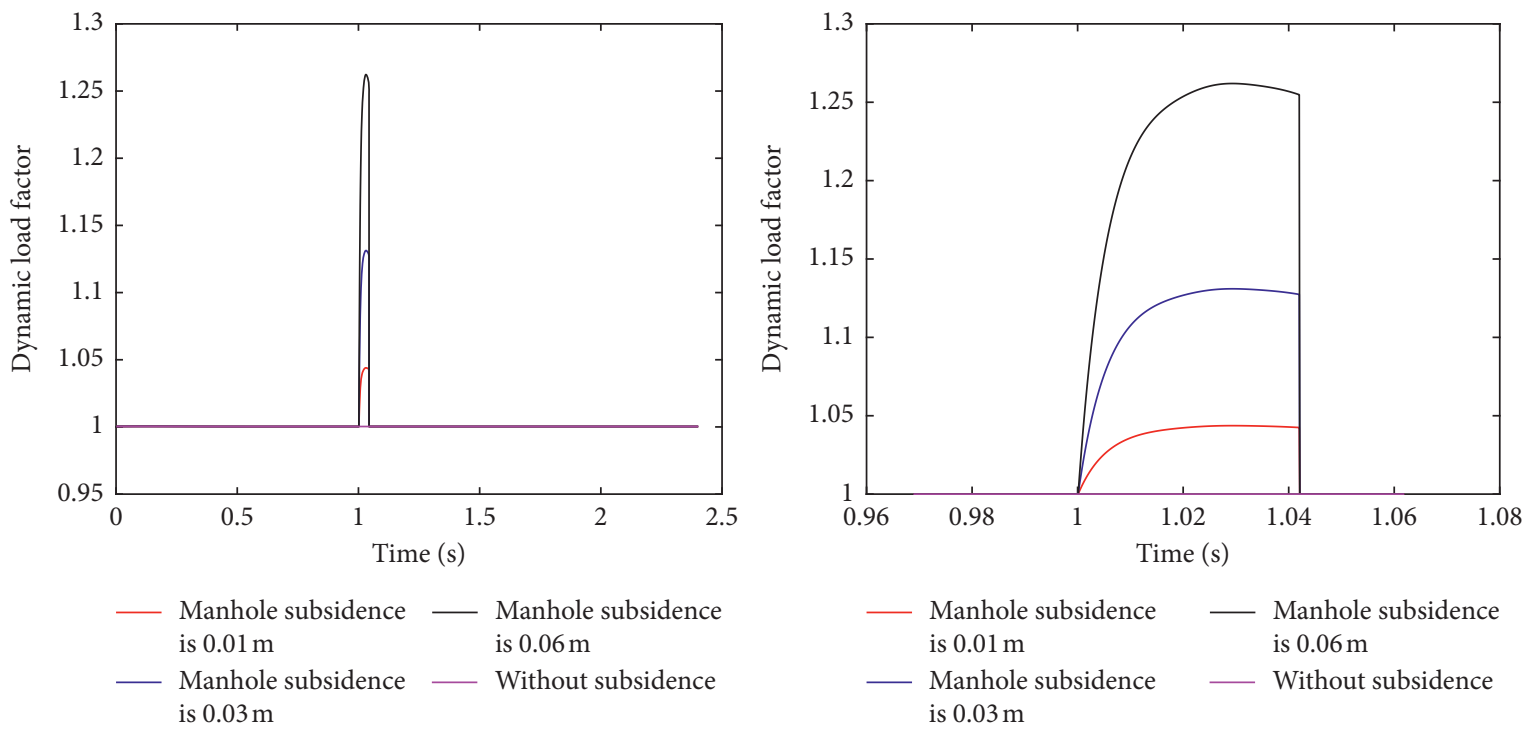

FIgURE 6: Vehicle dynamic load coefficient under different manhole subsidence values for car.

TABLE 4: Maximum dynamic load coefficient of the front wheel.

Working condition

Maximum dynamic load coefficient of truck

Maximum dynamic load coefficient of car

$(4 \%, 0.01 \mathrm{~m}, 30 \mathrm{~km} / \mathrm{h})$

6.1153

1.0437

$(4 \%, 0.03 \mathrm{~m}, 30 \mathrm{~km} / \mathrm{h})$

6.4632

1.1310

$(4 \%, 0.06 \mathrm{~m}, 30 \mathrm{~km} / \mathrm{h})$

6.9850

1.2620

curves of the pavement around the manhole under different longitudinal force of heavy truck are shown in Figure 12. It can be seen that the shear stress of the surface layer structure is the greatest, and it decreases rapidly with the increase of pavement depth. Therefore, the surface layer of the pavement around the manhole is more likely to produce crack damage under the action of shear stress. When the road depth is around 0.2 , there is a small step in the curves. This is the junction of the pavement surface layer and the base layer. The sudden change of shear stress will generate the relative displacement on the connection between the structural layers. When the relative displacement increases to a certain 


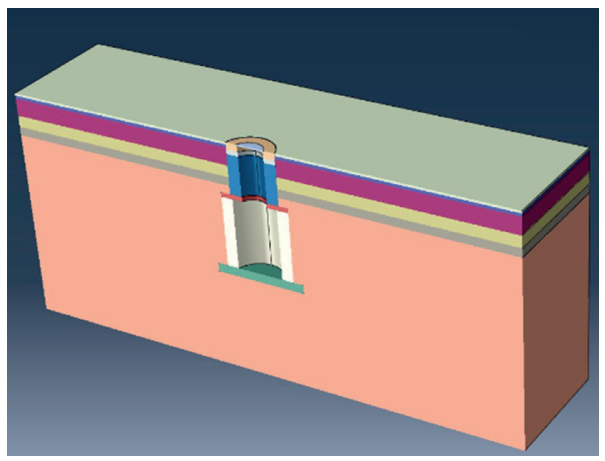

FIgURE 7: Three-dimensional pavement model with the manhole.

TABle 5: Pavement structure parameters.

\begin{tabular}{|c|c|c|c|c|c|}
\hline Layers & Material & Thickness $(\mathrm{cm})$ & $E(\mathrm{MPa})$ & Poisson's ratio & Damping \\
\hline Upper-surface layer & SMA-13 & 4 & - & 0.35 & 0.9 \\
\hline Middle-surface layer & SUP-20 & 6 & - & 0.35 & 0.9 \\
\hline Lower-surface layer & SUP-25 & 8 & - & 0.35 & 0.9 \\
\hline Base layer & Cement-stabilised macadam & 38 & 12000 & 0.25 & 0.4 \\
\hline Sub-base layer & Lime-stabilised soil & 20 & 5000 & 0.25 & 0.4 \\
\hline Subgrade layer & Subsoil & 324 & 81 & 0.4 & 0.4 \\
\hline
\end{tabular}

Table 6: Prony series coefficients of asphalt layers.

\begin{tabular}{|c|c|c|c|c|}
\hline \multirow{2}{*}{ Number of items } & \multirow{2}{*}{$\tau_{i}$} & \multicolumn{3}{|c|}{$g_{i}$} \\
\hline & & SMA-13 & Sup-20 & Sup-25 \\
\hline 1 & 0.000002 & 0.093359 & 0.09333 & 0.10241 \\
\hline 2 & 0.00002 & 0.15079 & 0.15075 & 0.15681 \\
\hline 3 & 0.0002 & 0.215671 & 0.21561 & 0.21202 \\
\hline 4 & 0.002 & 0.236076 & 0.23601 & 0.23542 \\
\hline 5 & 0.02 & 0.17431 & 0.17426 & 0.16681 \\
\hline 6 & 0.2 & 0.083306 & 0.08328 & 0.08494 \\
\hline 7 & 2 & 0.02903 & 0.02902 & 0.03022 \\
\hline 8 & 20 & 0.009295 & 0.00929 & 0.00755 \\
\hline 9 & 200 & 0.003249 & 0.00325 & 0.00248 \\
\hline 10 & 2000 & 0.001284 & 0.00128 & 0.00083 \\
\hline 11 & 20000 & 0.000591 & 0.00059 & 0.00032 \\
\hline 12 & 200000 & 0.000172 & 0.00017 & 0.00016 \\
\hline 13 & 2000000 & 0.000493 & 0.00048 & 0.00003 \\
\hline
\end{tabular}

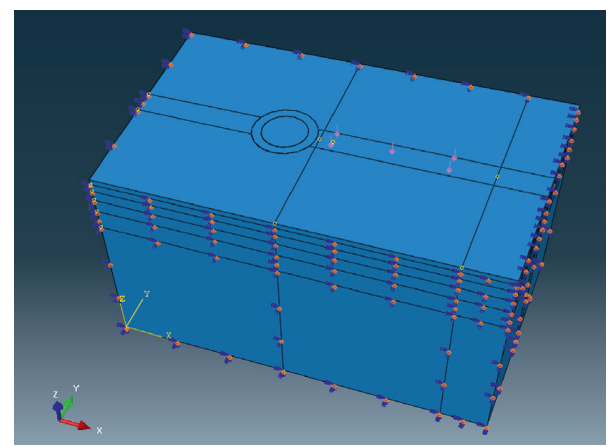

Figure 8: Processed model of pavement structure. 


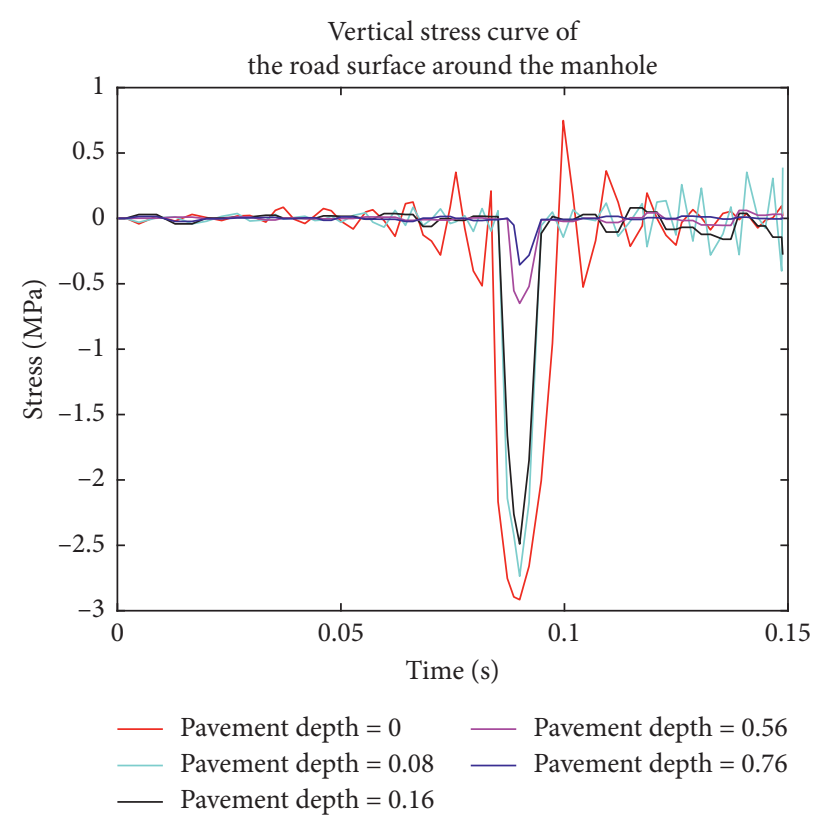

FIGURE 9: Vertical stress curve of the pavement around the manhole.

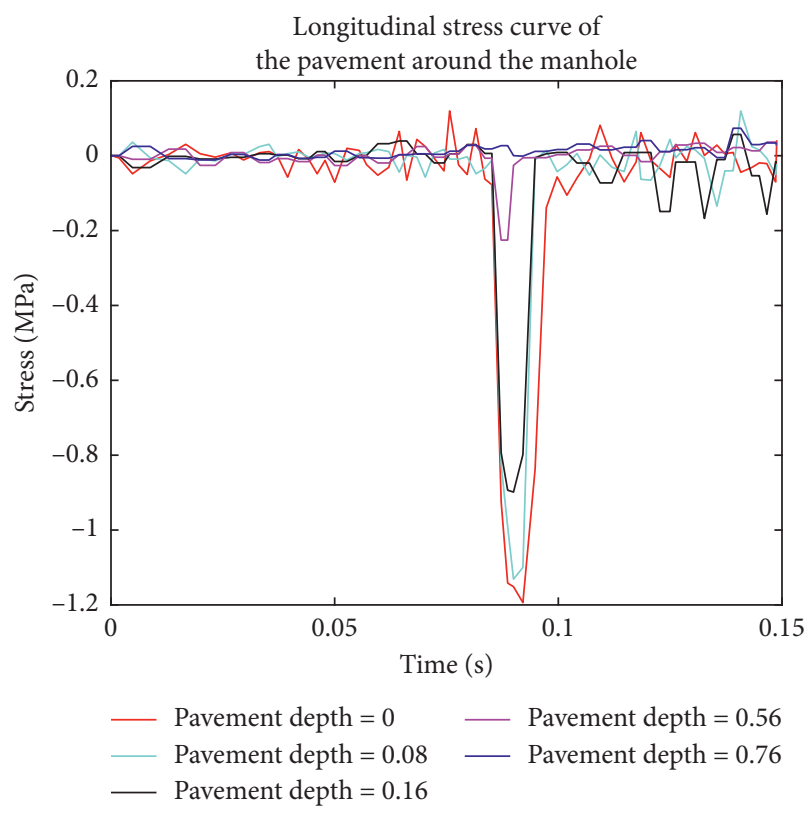

Figure 10: Longitudinal stress curve of the pavement around the manhole.

extent, the pavement surface layer will produce stripping damage.

Different vehicle types are selected to study the influence of vehicle types on the pavement around the manhole, including heavy truck and car. Under the load of the two types of vehicle, the pavement stress changes in a similar way. It can be seen in Figure 13 that with the increase of the manhole subsidence value, the pavement stress increases, and the stress decreases with the increase of the pavement depth, but there is a numerical difference. Because the weight and dynamic load

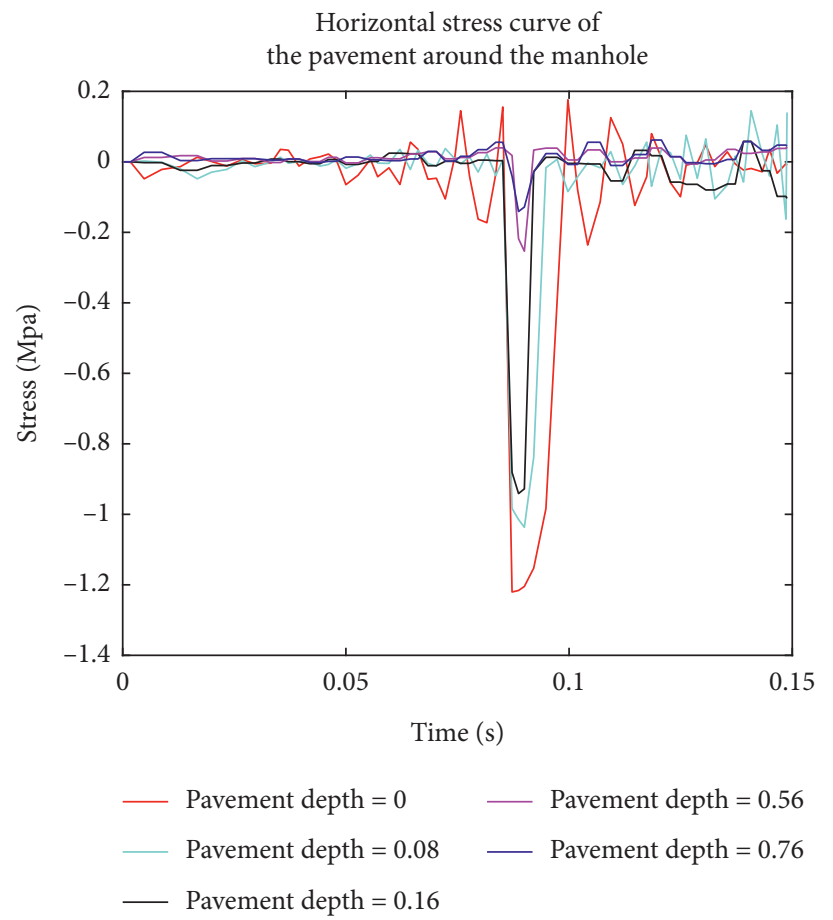

FIGURE 11: Horizontal stress of the pavement around the manhole.

coefficient of the truck are bigger than those of the car, it will cause greater stress and damage to the road.

\section{Fatigue Life Assessment of Asphalt Pavement around the Manhole}

4.1. Fatigue Life of the Pavement Surface Layer around the Manhole. In order to study the impact of different types of vehicles and different manhole subsidence values on the 


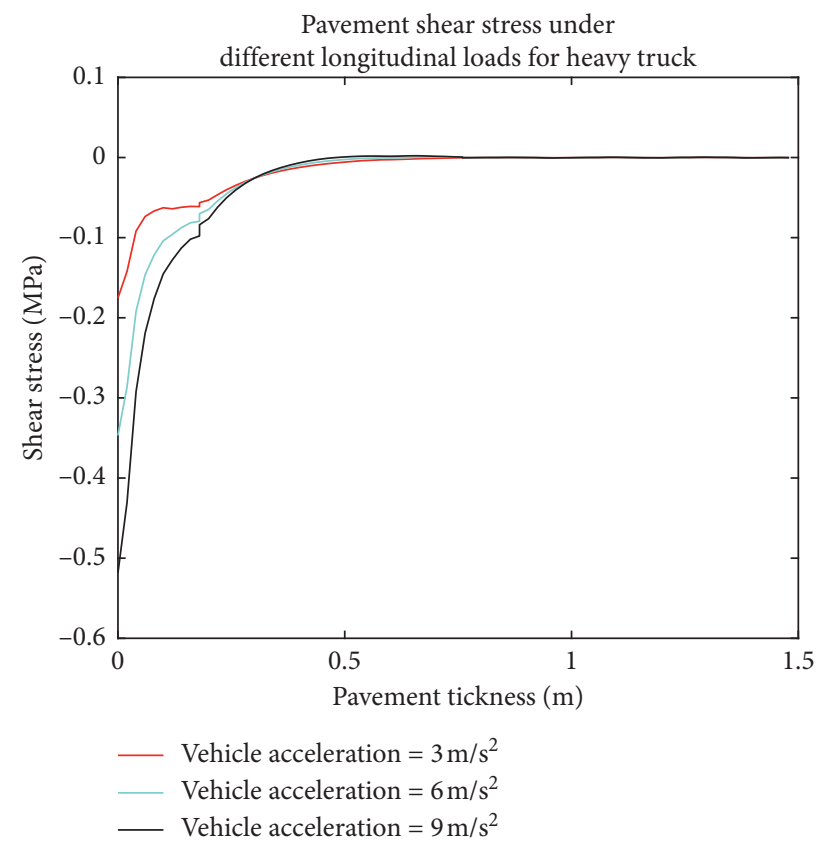

Figure 12: Pavement shear stress under different longitudinal forces of heavy truck.

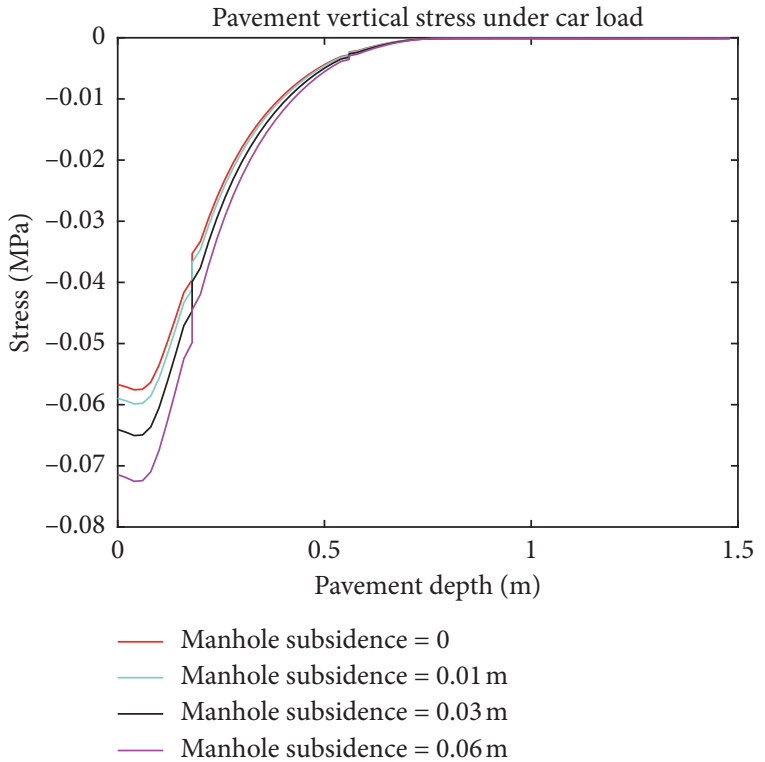

(a)

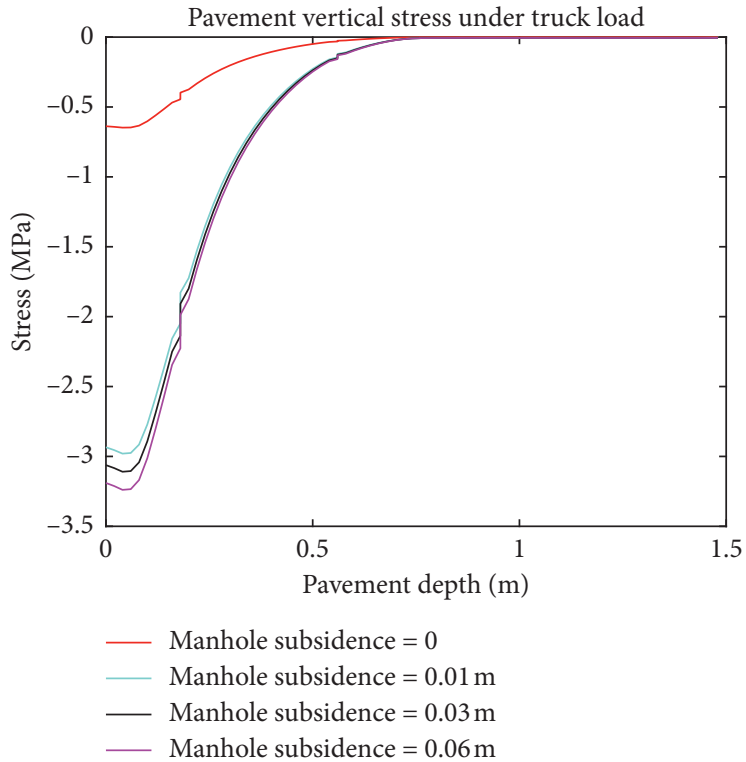

(b)

Figure 13: Pavement vertical stress under different vehicle loads. (a) Pavement vertical stress under car load. (b) Pavement vertical stress under heavy truck load.

fatigue life of the pavement surface layer, four loading conditions, shown in Table 7, are selected for both the car and heavy truck. Then, all the working conditions are simulated by finite element software.

Referring to the asphalt pavement design code of China [23], the fatigue life formula of asphalt mixture and the values according to the specification are as follows:
TABLe 7: Different loading conditions.

\begin{tabular}{lc}
\hline Working condition & Manhole subsidence value $(\mathrm{cm})$ \\
\hline Case 1 & 0 \\
Case 2 & 1 \\
Case 3 & 3 \\
Case 4 & 6 \\
\hline
\end{tabular}


TABle 8: The maximum bottom tensile strain and the fatigue life of pavement surface layer under different vehicle types and different loading conditions.

\begin{tabular}{lcccc}
\hline Working condition & Car & & Truck \\
& Maximum tensile strain & Fatigue life & Maximum tensile strain & Fatigue life \\
\hline Case 1 & $9.430 E-07$ & $2.34 E+10$ & $1.182 E-05$ & $1.02 E+06$ \\
Case 2 & $1.066 E-06$ & $1.44 E+10$ & $5.413 E-05$ & $2.43 E+03$ \\
Case 3 & $1.212 E-06$ & $8.62 E+09$ & $5.640 E-05$ & $2.07 E+03$ \\
Case 4 & $1.357 E-06$ & $5.51 E+09$ & $5.882 E-05$ & $1.75 E+03$ \\
\hline
\end{tabular}

$$
\begin{aligned}
N_{f} & =6.32 \times 10^{15.96-0.29 \beta} k_{a} k_{b} k_{T_{1}}^{-1}\left(\frac{1}{\varepsilon_{a}}\right)^{3.97}\left(\frac{1}{E_{a}}\right)^{1.58}(V F A)^{2.72}, \\
k_{b} & =\left[\frac{1+0.3 E_{a}^{0.43}(V F A)^{-0.85} e^{0.024 h_{a}-5.41}}{1+e^{0.024 h_{a}-5.41}}\right]^{3.33},
\end{aligned}
$$

$N_{f}$ is the fatigue life of asphalt mixture, $\beta$ is the target reliability index (the value is 1.04), $k_{a}$ is seasonal frozen land adjustment coefficient (the value is 0.9 ), $k_{T_{1}}$ is the temperature adjustment coefficient (the value is 10.81 ), $\varepsilon_{a}$ is the maximum tensile strain of the bottom layer of asphalt mixture obtained by the finite element analysis, $E_{a}$ is the compression modulus of asphalt mixture at a specific temperature (the value is $8000 \mathrm{MPa}$ ), VFA is the asphalt saturation (the value is $87 \%$ ), $h_{a}$ is the thickness of the asphalt layer (the value is $0.18 \mathrm{~m}$ in the pavement model), and $k_{b}$ is the load mode factor.

Through calculation, the maximum tensile strain at the bottom of the pavement asphalt layer and the corresponding fatigue life of pavement surface layer are shown in Table 8. It is shown that the vehicle type has a great influence on the fatigue life of the pavement surface layer around the manhole. Compared with the car, the tensile strain of the pavement under the heavy truck is larger and the fatigue life of the pavement surface layer is shorter. In addition, with the increase of manhole subsidence value, the tensile strain increases and the fatigue life of the pavement surface decreases significantly.

\subsection{Fatigue Life Assessment of Base Structure under Different} Influence Factors. The analysis result in Figure 13 shows that the pavement has the same stress law under the load of different types of vehicle, but the values are different. When the weight of the vehicle is larger, the stress and strain of the road increase obviously, which will seriously affect the fatigue life of the road as shown in Table 8. Therefore, the heavy truck is selected as the main vehicle type for the fatigue life assessment of the base layer of the pavement around the manhole.

In order to study the impact of different influence factors on the fatigue life of the pavement base layer around the manhole, the combination of manhole subsidence value, surface thickness, and soil elastic modulus is input into the FEA model. A total of eight cases are shown in Table 9.

Many countries have conducted in-depth research on the fatigue of base layer of the asphalt pavement, where three types of fatigue models and parameter values are chosen $[23,24]$. The tensile stress $\left(\sigma_{t}\right)$ of the base layer under eight cases is substituted into the fatigue models shown in Table 10.

It can be seen from Figures 14-16 that under the same working conditions, the fatigue life of the pavement base structure around the manhole changes in the same trend through three calculation models, but the absolute values are different. As shown in Figures 14(a)-16(a), the value of manhole subsidence has a great impact on the fatigue life of the pavement base structure around the manhole, and the life decreases with the increase of the subsidence value. The fatigue life of pavement base structure around the manhole without subsidence is much longer than the fatigue life of that with subsidence, but the gap decreases as the road depth increases. As shown in Figures 14(b)16(b), the change of elastic modulus of soil base has little influence on the fatigue life of upper base layer. And it has a relatively small effect on the lower part of the base layer, but it is not a linear positive correlation. From Figures 14(c)-16(c), it can be seen that the fatigue life of the pavement base structure increases with the increase in thickness of the surface layer.

As the fatigue life values are all in the K-th power of 10, the square root form is used to reduce the number of life times to eliminate the influence of the coordinate system so as to characterize the difference between the three different models more intuitively. The evaluation index $I$ based on the $\mathrm{K}$-th root of energy is constructed as follows:

$$
I=\sqrt[K]{E}=\sqrt[K]{\sum_{i=1}^{n}}(N f(i) * N f(i))
$$

where $N f$ is the life curve, $n$ is the number of data points in the fatigue curve, and $E$ is the energy of the signal. For the fatigue curve, $E$ quantifies the number of cycles of the fatigue curve obtained from the life model under this working condition, and $K$ is the conversion factor. The larger the index $I$ is, the larger the number of cycles given by the fatigue life model will be.

Figure 17 shows the results of evaluation factors based on higher root energy under three different fatigue life models. It can be seen from the figure that the results obtained by the fatigue life model of pavement base structure in China are the largest, followed by the results obtained from the Spanish model, and the results obtained from American model are the smallest. In addition, the law of fatigue life under each working condition reflected by the evaluation factor based on higher root energy is consistent with the original fatigue life curve. 
TABle 9: Different influence factors.

\begin{tabular}{lccc}
\hline Working condition & Manhole subsidence value $(\mathrm{cm})$ & Surface layer thickness $(\mathrm{cm})$ & Elastic modulus of soil base $(\mathrm{MPa})$ \\
\hline Case 1 & 0 & 18 & 81 \\
Case 2 & 1 & 18 & 81 \\
Case 3 & 3 & 18 & 81 \\
Case 4 & 6 & 18 & 81 \\
Case 5 & 1 & 10 & 81 \\
Case 6 & 1 & 30 & 81 \\
Case 7 & 1 & 18 & 30 \\
Case 8 & 1 & 18 & 120 \\
\hline
\end{tabular}

TABle 10: Fatigue model and corresponding parameter of base structure in various countries.

\begin{tabular}{|c|c|c|c|c|}
\hline Country & Fatigue model of base layer & Parameters & Parameter definition & Parameter value \\
\hline China & $N_{f}=K_{a} k_{T 2}^{-1} 10^{a-b\left(\sigma_{t} / R_{S}\right)+K_{C}-0.57 \beta}$ & $\begin{array}{c}K_{a} \\
K_{T 2} \\
K_{c} \\
R_{s} \\
a \\
b \\
\beta\end{array}$ & $\begin{array}{c}\text { Seasonal frozen land adjustment coefficient } \\
\text { Temperature adjustment coefficient } \\
\text { Field comprehensive correction factor } \\
\text { Flexural-tensile strength } \\
\text { Fatigue test regression coefficient } \\
\text { Fatigue test regression coefficient } \\
\text { Target reliability index }\end{array}$ & $\begin{array}{c}0.9 \\
2.79 \\
12.47 \\
4.2 \mathrm{MPa} \\
13.24 \\
12.52 \\
1.04 \\
\end{array}$ \\
\hline USA & $\log N_{f}=\left(0.972 \beta_{c 1}-\left(\sigma_{t} / M R\right)\right) / 0.0825 \beta_{c 2}$ & $\begin{array}{l}M R \\
\beta_{c 1} \\
\beta_{c 2} \\
\end{array}$ & $\begin{array}{l}\text { Modulus of rupture } \\
\text { Field-shift adjustment constant } \\
\text { Field-shift adjustment constant }\end{array}$ & $\begin{array}{c}1.5 \mathrm{MPa} \\
1.0 \\
1.0 \\
\end{array}$ \\
\hline Spain & $\sigma_{t} / R_{F, L T}=\gamma\left(1-\alpha \log N_{f}\right)$ & $\begin{array}{c}R_{F, L T} \\
\gamma \\
\alpha\end{array}$ & $\begin{array}{l}\text { Flexural-tensile strength } \\
\text { Fatigue test regression coefficient } \\
\text { Fatigue test regression coefficient }\end{array}$ & $\begin{array}{c}2 \mathrm{MPa} \\
0.8 \\
0.065\end{array}$ \\
\hline
\end{tabular}

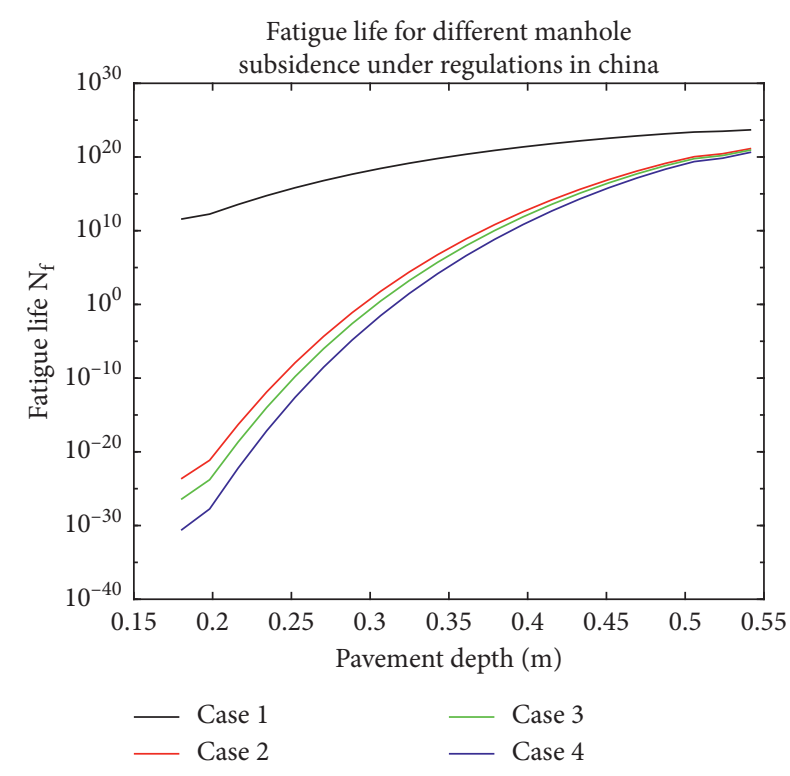

(a)

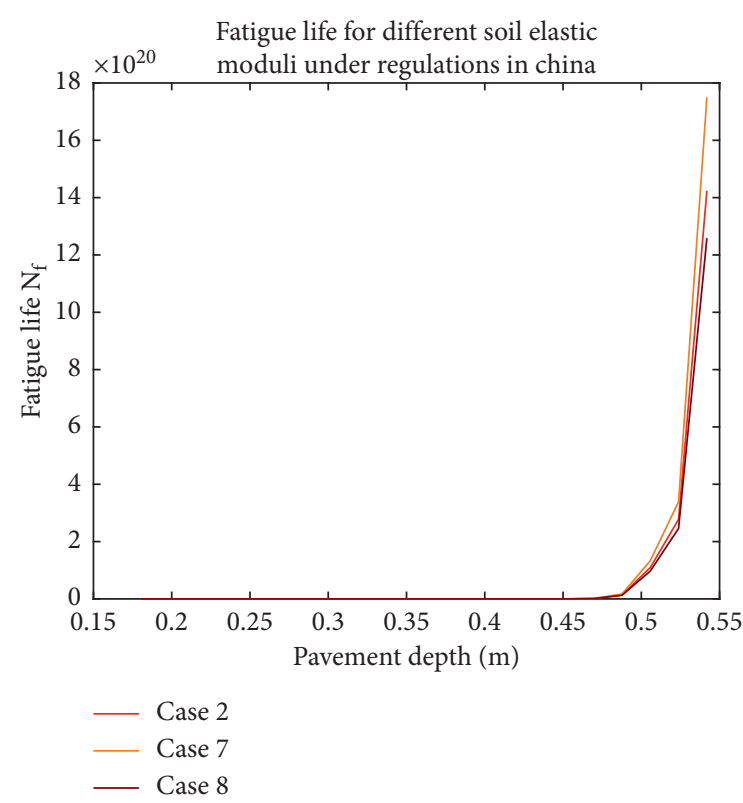

(b)

Figure 14: Continued. 


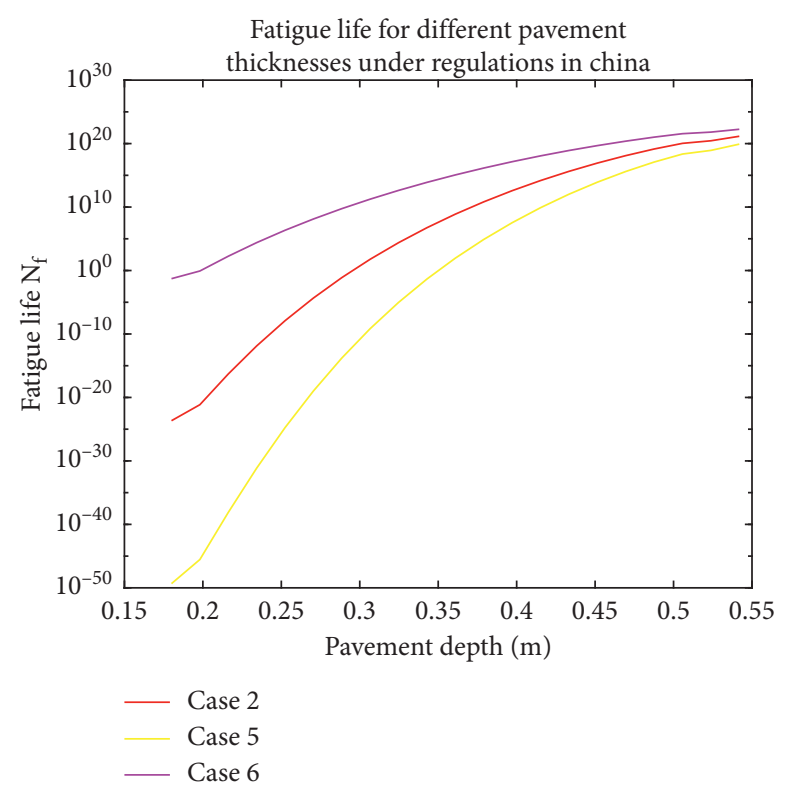

(c)

Figure 14: Fatigue life of pavement base layer for different cases under regulations in China. (a) Different manhole subsidence values. (b) Different soil elastic moduli. (c) Different surface layer thicknesses.

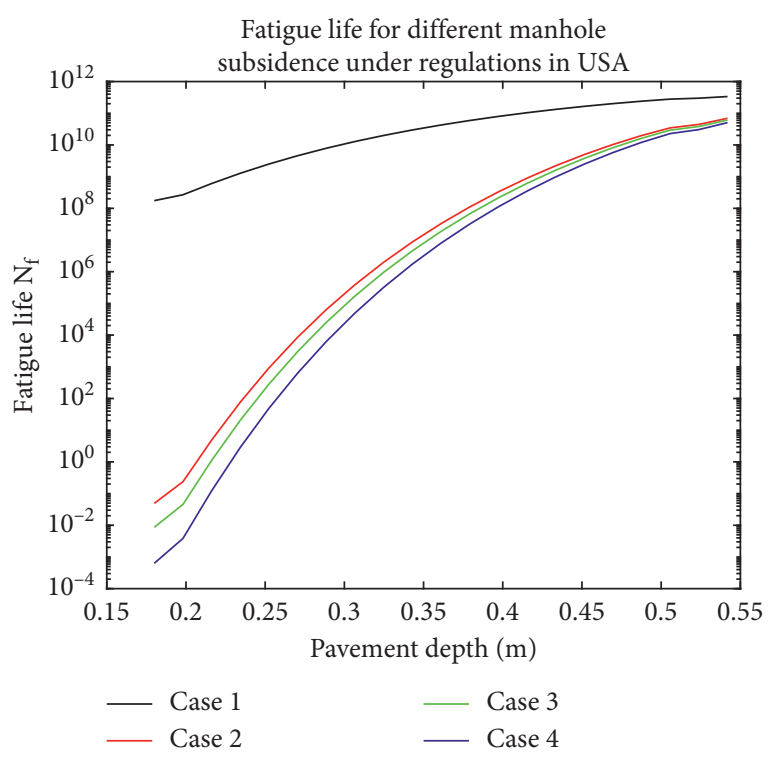

(a)

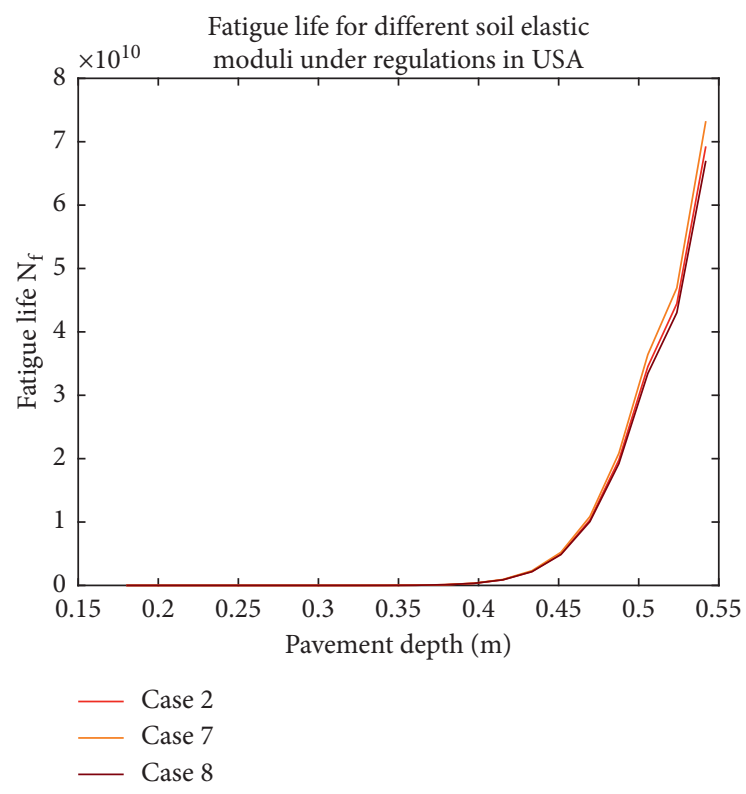

(b)

FIGURE 15: Continued. 


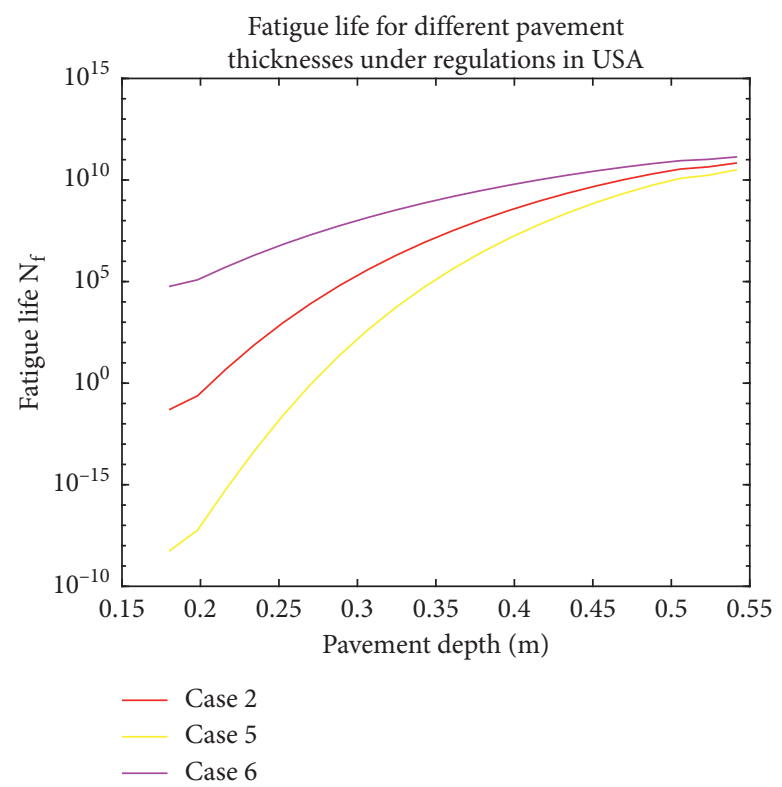

(c)

Figure 15: Fatigue life of pavement base layer for different cases under regulations in USA. (a) Different manhole subsidence values. (b) Different soil elastic moduli. (c) Different surface layer thicknesses.

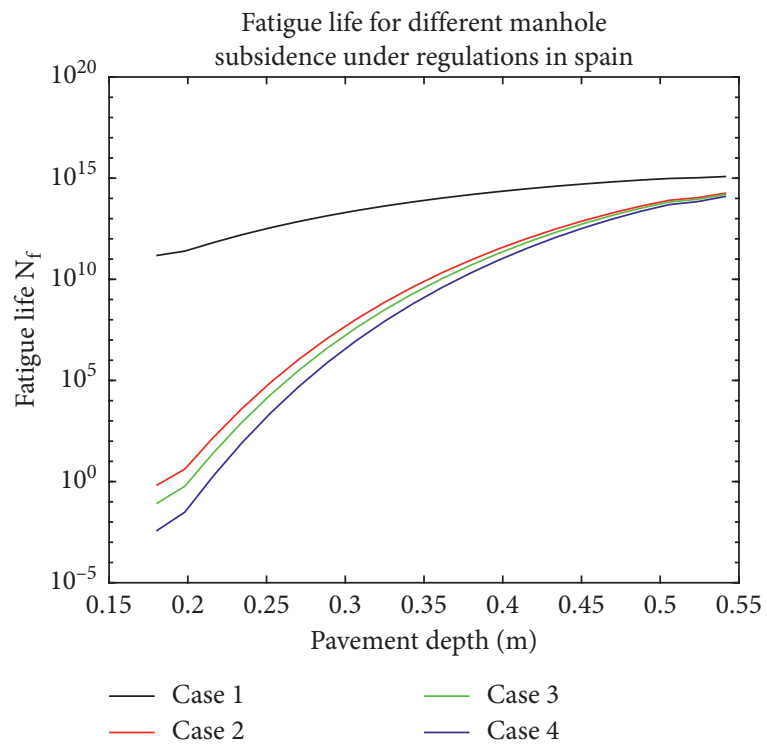

(a)

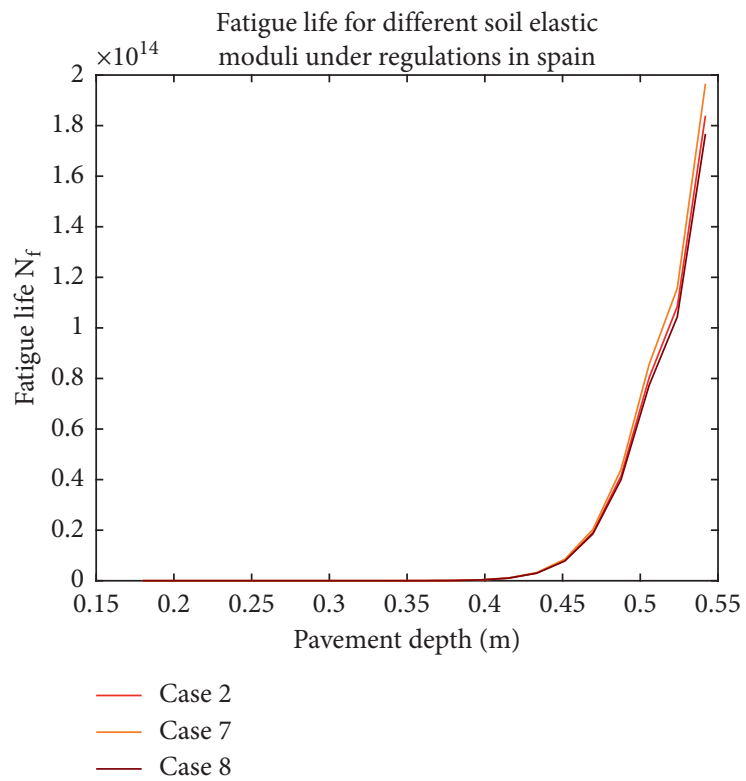

(b)

Figure 16: Continued. 


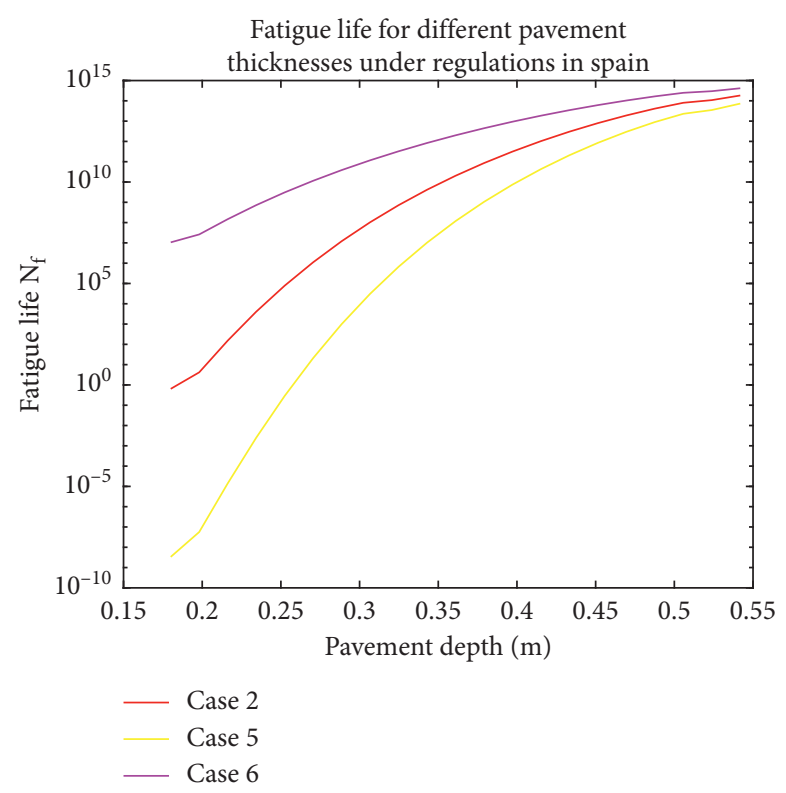

(c)

FIgURE 16: Fatigue life of pavement base layer for different cases under regulations in Spain. (a) Different manhole subsidence values. (b) Different soil elastic moduli. (c) Different surface layer thicknesses.

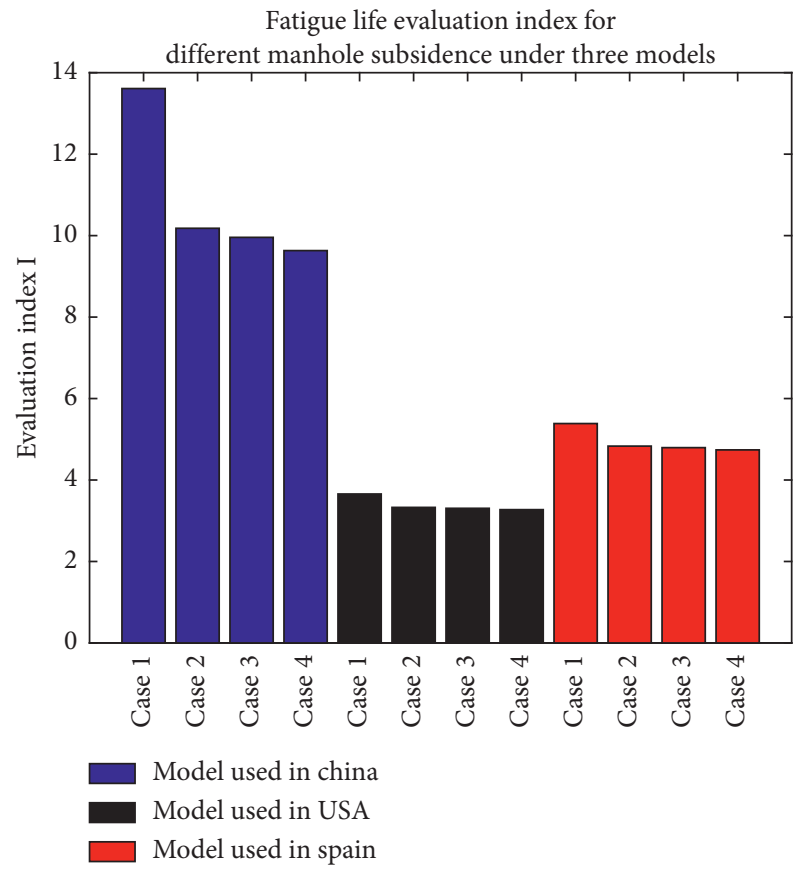

(a)

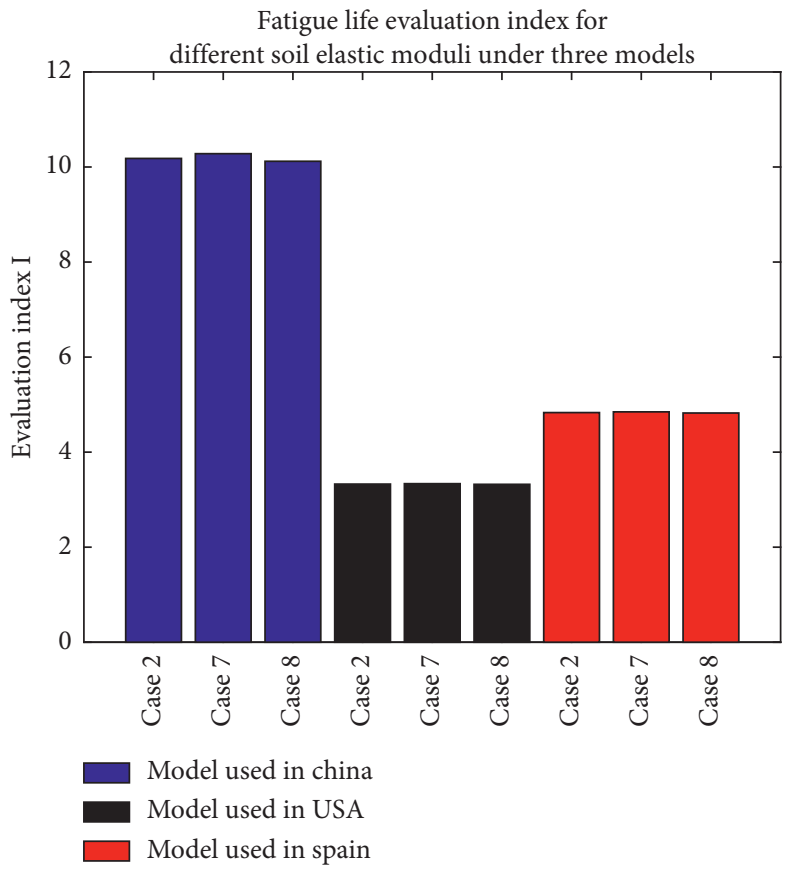

(b)

FIGURE 17: Continued. 


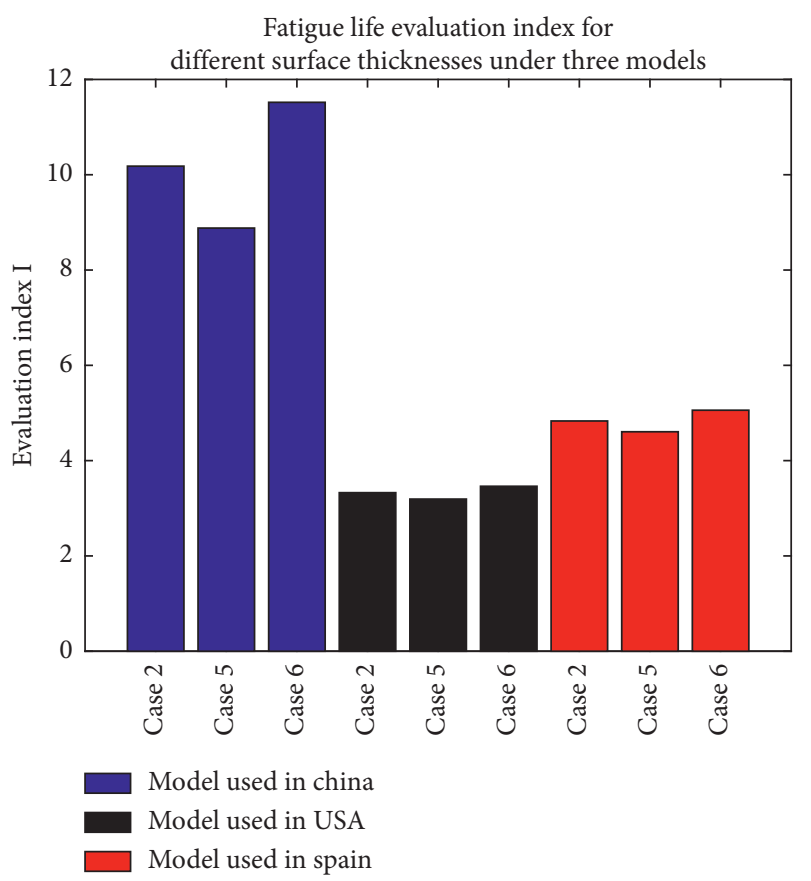

(c)

Figure 17: Comparative analysis of three fatigue models under different influence factors. (a) Different manhole subsidence values. (b) Different soil elastic moduli. (c) Different surface layer thicknesses.

\section{Conclusions}

This paper proposed an effective way to analyse the stress characteristics of the road under vehicle load and evaluate the fatigue life of the pavement around the manhole. A half vehicle-pavement-manhole cover coupling dynamic model was established to simulate the interaction between vehicle and road. Considering different types of vehicle passing through the pavement around the manhole, the dynamic load coefficients of the front wheels under different conditions were solved.

The dynamic stress responses of different pavement layers around the manhole under vertical and longitudinal loads were obtained by the FEA model in ABQUS. According the dynamic stress analysis, when load enters and leaves the loading area, the stresses of surface layer and the base layer in the pavement around the manhole present the phenomenon of positive and negative alternations, which is the reason for fatigue damage. The pavement stress under truck load is greater than that under car load, but the change rules are similar. The stress decreases gradually with the increase of pavement depth, and the maximum stress occurs at the road surface layer. When the longitudinal load of the vehicle increases, the longitudinal shear stress of the pavement increases significantly, and there is a small step at the junction of the surface layer and the base layer, which may cause relative displacement damage between these two layers.

In addition, the fatigue life of the pavement surface layer under different types of vehicles and different loading conditions was calculated, and three different fatigue life models were selected to analyse the influence of different factors on the fatigue life of the pavement base structure around the manhole. The results indicated that the fatigue life of the pavement base layer decreased with the increase of manhole subsidence value, and the fatigue life increased with the increase in thickness of the surface layer, and the change of elastic modulus of the subgrade has no obvious influence on the fatigue life of road base. Finally, a fatigue life evaluation index based on high root energy was constructed, which not only was consistent with the law reflected by the original fatigue life curve but also could parallelly compare the results of three models more intuitively.

\section{Data Availability}

The data used to support the analysis of this paper are included within the article.

\section{Conflicts of Interest}

The authors declare that there are no conflicts of interest regarding the publication of this paper.

\section{References}

[1] H. Li, Prevention and Treatment Research on Pavement Distresses Around Inspection Wells, Hebei University of Technology, Tianjin, China, 2014.

[2] B. A. Usama, "Distresses around manholes," International Journal of Advanced Science and Technology, vol. 29, no. 8s, pp. 2894-2900, 2020.

[3] H. Wang, J. Zhao, X. Hu, X. Zhang, and Z. Xia, "Flexible pavement response analysis under dynamic loading at different vehicle speeds and pavement surface roughness 
conditions," Journal of Transportation Engineering, vol. 146, no. 3, 2020.

[4] J. Qian, R. Zhou, S. Chen, X. Gu, and M. Huang, "Influence of pavement roughness on dynamic stresses in saturated subsoil subjected to moving traffic loading," International Journal of Geomechanics, vol. 18, no. 4, 2018.

[5] D.-S. Ling, Y. Zhao, B. Huang, F. Zhang, and Y. Zhou, "Analysis of dynamic stress path in inhomogenous subgrade under moving aircraft load," Soil Dynamics and Earthquake Engineering, vol. 111, pp. 65-76, 2018.

[6] P. Galvín, A. Romero, and J. Domínguez, "Fully three-dimensional analysis of high-speed train-track-soil-structure dynamic interaction," Journal of Sound and Vibration, vol. 329 , no. 24 , pp. 5147-5163, 2010.

[7] M. Eslaminia and M. N. Guddati, "Fourier-finite element analysis of pavements under moving vehicular loading," International Journal of Pavement Engineering, vol. 17, no. 7, pp. 602-614, 2016.

[8] W. Hu, Q. Zhao, Y. Liu, Z. Li, and X. Kong, "Damage evaluation of the paving around manholes under vehicle dynamic load," Advances in Materials Science and Engineering, vol. 2020, Article ID 6510439, 11 pages, 2020.

[9] Z. Yan, E. Chen, Z. Wang, and C. Si, "Research on mesoscopic response of asphalt pavement structure under vibration load," Shock and Vibration, vol. 2019, Article ID 2620305, 13 pages, 2019.

[10] L. Wei, H. Li, and X. Ma, "Mechanics analysis and disease prevention of the pavement around inspection well using ABAQUS," Journal of Chongqing Jiaotong University (Natural Science), vol. 35, no. 4, pp. 25-28, 2016.

[11] S. F. Brown and C. J. Brown, "The structural characteristics of manhole installations in pavements," Proceedings of the Institution of Civil Engineers-Transport, vol. 135, no. 4, pp. 201-208, 1999.

[12] J.-D. Lin, H.-H. Chen, W.-H. Huang, Y.-W. Weng, L.-H. Yeh, and P.-H. Sung, "Numerical modeling of composite materials for the alleviation of manhole decrement into pavement," Journal of Computational and Theoretical Nanoscience, vol. 13, pp. 373-376, 2012.

[13] D. Zhou, Z. Ma, L. Liu, and L. Sun, "Study on fatigue performance of in-service asphalt pavement based on full-scale accelerated loading test," Journal of Highway and Transportation Research and Development, vol. 37, no. 1, pp. 17-24, 2020.

[14] D. M. Dilip, P. Ravi, and G. L. S. Babu, "System reliability analysis of flexible pavements," Journal of Transportation Engineering, vol. 139, no. 10, pp. 1001-1009, 2013.

[15] C. Hintz and H. Bahia, "Understanding mechanisms leading to asphalt binder fatigue in the dynamic shear rheometer," Road Materials and Pavement Design, vol. 14, no. 21, pp. 231-251, 2013.

[16] L. Ning, A. A. A. Molenaara, M. F. C. Van De Ven, and S. Wu, "Characterization of fatigue performance of asphalt mixture using a new fatigue analysis approach," Construction and Building Materials, vol. 45, pp. 45-52, 2013.

[17] D. Yared and B. Bjorn, "Effects of truck traffic on top-down fatigue cracking performance of flexible pavements using a new mechanics-based analysis framework," Road Materials and Pavement Design, vol. 19, no. 1, pp. 182-200, 2018.

[18] CJJ 37-2012, Code for Design of Urban Road Engineering, Ministry of Housing and Urban-Rural Development of the People's Republic of China, Beijing, China, 2012.

[19] Q. Zhao, Z. Li, W. Hu, X. Meng, and H. Zhang, "Driving comfort evaluation for manhole covers and pavement around manholes," Advances in Materials Science and Engineering, vol. 2019, pp. 1-10, Article ID 1293619, 2019.

[20] J. Zhou, Settlement Law and Improvement Measures of the Manhole on the Roadway, Chongqing University, Chongqing, China, 2013.

[21] Y. Xie, Calculation Method of Vehicle Dynamic Response on Uneven Pavement, Chongqing Jiangtong University, Chongqing, China, 2014.

[22] R. Yan, The Simulation and Analysis of Fourteen-DegreeFreedom Vehicle Dynamic Model, Hunan University, Changsha, China, 2014.

[23] China Communications Press Co., Ltd., Specifications for Design of Highway Asphalt Pavement, China Communications Press Co., Ltd., Beijing, China, 2017.

[24] Y. Zhu, Research on Design Controlling Index for Semi-rigid Base Asphalt Pavement, Southeast University, Nanjing, China, 2019.

[25] Y. Zhao and Z. H. O. N. G. Yang, "Dynamic viscoelastic analysis of asphalt pavements," Journal of Vibration and Shock, vol. 28, no. 9, pp. 159-162, 2009.

[26] Li Qian, Research on Dynamic Interaction of Vehicle-Asphalt Pavement Structure System and the Pavement Damage Mechanism, Xi'an University of Architecture \& Technology, Xi'an, China, 2018. 